IZA DP No. 7863

Migrant Networks and the Spread of Misinformation

Benjamin Elsner

Gaia Narciso

Jacco J. J. Thijssen

December 2013 


\title{
Migrant Networks and the Spread of Misinformation
}

\author{
Benjamin Elsner
}

$I Z A$

Gaia Narciso

Trinity College Dublin, CReAM and IIIS

\author{
Jacco J. J. Thijssen \\ University of York
}

\section{Discussion Paper No. 7863 \\ December 2013}

\author{
IZA \\ P.O. Box 7240 \\ 53072 Bonn \\ Germany \\ Phone: +49-228-3894-0 \\ Fax: +49-228-3894-180 \\ E-mail: iza@iza.org
}

Any opinions expressed here are those of the author(s) and not those of IZA. Research published in this series may include views on policy, but the institute itself takes no institutional policy positions. The IZA research network is committed to the IZA Guiding Principles of Research Integrity.

The Institute for the Study of Labor (IZA) in Bonn is a local and virtual international research center and a place of communication between science, politics and business. IZA is an independent nonprofit organization supported by Deutsche Post Foundation. The center is associated with the University of Bonn and offers a stimulating research environment through its international network, workshops and conferences, data service, project support, research visits and doctoral program. IZA engages in (i) original and internationally competitive research in all fields of labor economics, (ii) development of policy concepts, and (iii) dissemination of research results and concepts to the interested public.

IZA Discussion Papers often represent preliminary work and are circulated to encourage discussion. Citation of such a paper should account for its provisional character. A revised version may be available directly from the author. 
IZA Discussion Paper No. 7863

December 2013

\section{ABSTRACT}

\section{Migrant Networks and the Spread of Misinformation*}

Diaspora networks provide information to future migrants and influence both their decision to migrate and their success in the host country. While the existing literature explains the effect of networks on migration decisions through the size of the migrant community, we show that the quality of the network is an equally important determinant. We argue that networks that are more integrated in the society of the host country can give more accurate information about job prospects to future migrants. In a decision model with imperfect signalling we show that migrants with access to a better network are more likely to make the right decision - they migrate only if they gain - and they migrate earlier. We test these predictions empirically using data on recent Mexican migrants to the US, and exploit the geographic diffusion of Mexicans since the 1980s as well as the settlement of immigrants that came during the Bracero program in the 1950s to instrument for the quality of networks. The results provide strong evidence that connections to a better-integrated network lead to better outcomes after migration. Yet we find no evidence that the quality of the network affects the timing of migration.

JEL Classification: F22, J15, J61

Keywords: diasporas, information, migration

Corresponding author:

Benjamin Elsner

IZA

P.O. Box 7240

53072 Bonn

Germany

E-mail: elsner@iza.org

\footnotetext{
* We would like to thank Simone Bertoli, Herbert Brücker, Joanna Clifton-Sprigg, Tommaso Colussi, Margherita Comola, Christian Danne, Rachel Griffith, Joachim Jarreau, Julia Matz, Imran Rasul, Bas ter Weel, Mathis Wagner, and seminar participants at IZA, University College Dublin, the University of Southern Denmark, as well as the conferences ISNE, TEMPO, IEA, ESEM, OECD immigration workshop, RES, NORFACE, ESPE, EALE, IZA/SOLE for helpful comments. Elsner gratefully acknowledges funding from the Irish Research Council for the Humanities \& Social Sciences (IRCHSS).
} 


\section{INTRODUCTION}

Prior to moving, migrants face significant uncertainty about their job prospects abroad, which is why they often seek advice from existing diaspora networks. A large literature has shown that diaspora networks indeed influence the decision to migrate and affect the success of migrants in the host country. The size of a network has been identified in this literature as the main determinant. In this paper we provide a different perspective on the role of diaspora networks, by showing that the quality of these networks - measured by their degree of integration in the host society - has an equally important impact on the decisions and success of future migrants.

We argue that the integration of migrant networks in the host country determines both the decision to migrate and the outcomes after migration. Because existing networks differ in their degree of integration, some networks are able to provide more accurate information on job prospects than others. Well-integrated networks that have lots of interaction with the world that surrounds them have a better knowledge of local labor markets than enclaves, whose members typically have little social interaction outside the network. Potential migrants with access to a better-integrated network can base their decision on more accurate information, which in turn makes them more likely to make a correct decision: they migrate if they can expect to get a job that makes them better off, and they stay if they can expect a job that makes them worse off.

To fix ideas, we explore the link between information flows and the success of migrants in a 2-period decision model. Initially the migrant has some knowledge about her expected income abroad, but not enough to convince her that migration will make her better off. She then receives information from the network and updates her beliefs about expected income from migration. A more integrated network provides a more truthful signal and spreads less misinformation, such that a migrant who receives this information is more likely to make the right decision given her true income prospects in the receiving country.

In a further step we extend the model to a dynamic framework and study the effect of network quality on the timing of migration. In this setting, the migrant receives a signal from the network in every period, and faces the trade-off between migrating now and waiting to receive more information from the network. With every signal she updates her beliefs, and learns over time about the true odds of getting a good job abroad. The timing of migration is the solution of an optimal stopping problem, in which the migrant has to weigh the gains from more certainty in the future against the opportunity cost of waiting for another period. She emigrates once she has enough evidence that migration is 
beneficial. This threshold is reached earlier by migrants with access to a more integrated network, as every signal contains more accurate information.

We test the theoretical predictions using data on recent Mexican immigrants in the US. Mexican communities are spread out all across the US, which allows us to exploit a significant degree of variation in the characteristics of these communities. Mexican communities in traditional destinations such as Los Angeles and Houston are typically more enclaved than communities in newer destinations.

Key to the empirical analysis is measuring both the quality of the network and the success of immigrants. For the quality of the network we compute an assimilation index, which measures the degree of similarity between Mexicans and Americans in an area with respect to a wide range of characteristics. The choice of this proxy follows the observation in the social networks literature that people with similar characteristics have more interaction. More interaction in turn leads to a more efficient aggregation of information, and ultimately to more accurate information on job prospects that can be passed on to future migrants. To measure the success of migrants, we take the difference between wages of Mexicans in the US and in Mexico. As the data do not allow us to observe Mexicans in both countries at the same time, we predict counterfactual wages in Mexico based on observable characteristics. A larger difference between income in the US and Mexico means that a migrant was less likely to make a mistake in her decision to migrate.

We address the potential endogeneity that arises from unobserved factors with two instrumental variables: the change in the concentration of Mexicans in local areas in the 1980s, and the settlement patterns of low-skilled Mexicans that came during the Bracero program from 1942 to 1964. As we show, both are significant predictors of the assimilation of the network. Both a larger change in the concentration in the 1980s and a larger share of Bracero immigrants are associated with a significantly lower degree of assimilation of networks today. We also demonstrate that the assimilation of Mexican communities is persistent over time, while there is little persistence in the success of migrants that moved to the same area. This observation gives us confidence that changes to the network quality that happened between 20 and 50 years ago affect the success of current migrants through the characteristics of networks but not through other channels.

Our results are consistent with the first theoretical prediction. Migrants with access to better integrated networks are significantly more likely to be better-off compared to staying in Mexico. A one standard deviation increase in the assimilation index increases the monthly income difference between the US and Mexico by 90USD. Yet the data do not confirm our second hypothesis that better networks lead to earlier migration. We 
discuss several possibilities why we cannot find an effect different from zero.

This paper contributes to five strands of the literature. First, it provides a new perspective to the literature on network effects in international migration. In large parts, the literature defines a network as the number of previous migrants in a given destination and studies how existing networks affect the decisions and outcomes of future migrants. One strand of this literature documents that migration is path-dependent; new migrants move to places where they find an established community from their home countries (Pedersen et al. 2008; Beine et al., 2010). Other papers argue that larger networks are associated with a negative selection of migrants. Larger networks decrease the moving costs, so that migration becomes profitable even for less-skilled workers (Carrington et al. 1996; Winters et al., 2001; Munshi, 2003; McKenzie \& Rapoport, 2010; Beine et al., 2011). As shown by Umblijs (2012), larger networks attract more risk averse migrants, while riskloving migrants tend to move to smaller networks. This paper, by contrast, focuses on the quality of migrant networks as a driver of migration flows, and demonstrates that, in addition to the size of a network, its quality affects the success of migrants.

More broadly, the paper adds to the literature on aggregation and propagation of information in social networks. The theoretical literature has established that information spreads faster in loosely connected networks (Jackson \& Rogers, 2007), and false beliefs are less likely to stick (Acemoglu et al. 2010; Golub \& Jackson, 2010, 2012), because each member of a loosely connected group receives more information from members with many contacts outside the group. These predictions have been confirmed in recent empirical work, both at the micro and macro-level. Alatas et al. (2012) show that better-integrated networks are better at assessing the poverty status of inhabitants of Indonesian villages. At the macro-level, Eagle et al. (2010) give evidence that British communities with more connections to other communities have a higher GDP, while Fogli \& Veldkamp (2012) find a causal link between better-integrated networks and long-run economic development. While all these papers link the social structure of networks to information flows and outcomes within a community, this paper illustrates how the ability of a community to aggregate information also has an impact on outsiders that receive this information.

Third, it adds to the literature on the role of information in migration decisions. As shown by Bertoli (2010), the selection of migrants can change significantly once there is uncertainty about wages abroad. This hypothesis is confirmed by McKenzie et al. (2013), who demonstrate that Tongan migrants to New Zealand have incorrect beliefs about their employment and earnings prospects abroad. One explanation they offer is that migrant networks deliberately report lower earnings to their families at home to 
mitigate the pressure to send remittances. Moreover, the available information affects the the scale of migration flows. As shown by Farré \& Fasani (2013) for Indonesia, access to cable TV significantly reduces internal migration, because workers have more information about labor markets in their potential destinations. In a recent study, Batista \& Narciso (2013) stress the importance of the quality and frequency of information flows for the flow of remittances. They use a randomised control trial to increase the communication flows between immigrants and their networks abroad by providing calling credit to the treatment group, and show that increased communication flows lead to higher and more productively used remittances. Our paper introduces the integration of networks in the host society as an additional channel through which information can influence migration decisions.

Fourth, the paper extends the literature on the impact of ethnic enclaves on the labour market outcomes of immigrants. Borjas (1995) shows that enclaves create human capital externalities that persist over generations. Children in ethnic enclaves grow up in the same closed-up environment, which leads to a persistence in skill differentials compared to people outside the enclave. Yet enclaves can also have a positive impact on the labour market outcomes of immigrants. Edin et al. (2003) find a large positive effect of ethnic concentration on the earnings of low-skilled immigrants in Sweden. As Andersson et al. (2009) show, the concentration of immigrants also increases the likelihood of getting a job for new immigrants. While these papers document the impact of networks on the outcomes of immigrants that have already emigrated, our paper shows that networks can even have an impact on migration decisions before emigration. Not only do migrant networks provide help in finding a job once a migrant has arrived, they also provide information to potential migrants in their home country.

Finally, the paper relates to the literature on the optimal timing of migration. This strand of the literature began with Burda (1995), who shows in a real options model that increased uncertainty about job prospects can lead to considerable delays in the migration decision. Moretto \& Vergalli (2008) and Vergalli (2008) show in a similar framework that the timing of migration can be driven by networks that facilitate the integration abroad. Our dynamic decision framework builds on a similar methodology, but we explicitly model the relation between networks, information flows and the migration decision, which allows us to compare the success and the optimal time to migrate for networks with different degrees of integration. 


\section{Migrant Networks as Providers of INFORMATION}

Our basic argument is that migrant communities that are more integrated in the society of their host country are able to give better information to future migrants. Members of a more integrated community have a better knowledge of the labor market and can give future migrants more accurate information about job prospects. This argument is consistent with the strength-of-weak-ties hypothesis (Granovetter, 1973, 2005), which states that in many situations acquaintances - weak ties - are able to provide more important information than close family and friends - strong ties, because acquaintances have less overlap in their social contacts and receive information from outside one's own network. In contrast, close friends and family are more likely to have the same contacts and information sources, so that information easily becomes redundant.

Two examples for migrant networks with different degrees of integration are illustrated in Figure 1. The figure on the left describes an ethnic enclave. Its members, represented by the circles, have close connections within the network but very few connections to the outside world, represented by the crosses. An enclave is a typical example for a network with a high degree of closedness. This is a pervasive pattern in social networks, to which the literature often refers as inbreeding homophily — the fact that individuals with similar characteristics form close ties among each other (McPherson et al., 2001; Currarini et al., 2009). Examples for such closed-up migrant networks are Mexican neighbourhoods in Los Angeles or Chinatowns in most North American cities. The graph on the right represents a well-integrated network, whose members have weak connections among each other but strong connections to the outside world. Examples for such groups are the Germans in London or the Dutch in New York.

There are two reasons why a potential migrant should receive better information from a well-integrated network than from an enclave. First, the well-integrated network has more connections to the outside world. Its members receive more information and therefore have better knowledge about job perspectives in the receiving country. Members of an enclave, by contrast, typically have little knowledge of the language of the host country (Lazear, 1999, Bauer et al., 2005, Beckhusen et al., 2012), which makes interactions with natives difficult. An enclave may offer job opportunities within the migrant community, but it has very limited information on the labor market outside the enclave.

Second, members of the well-integrated network only have weak ties among each other, so that misinformation - false beliefs about the world outside the network — is 

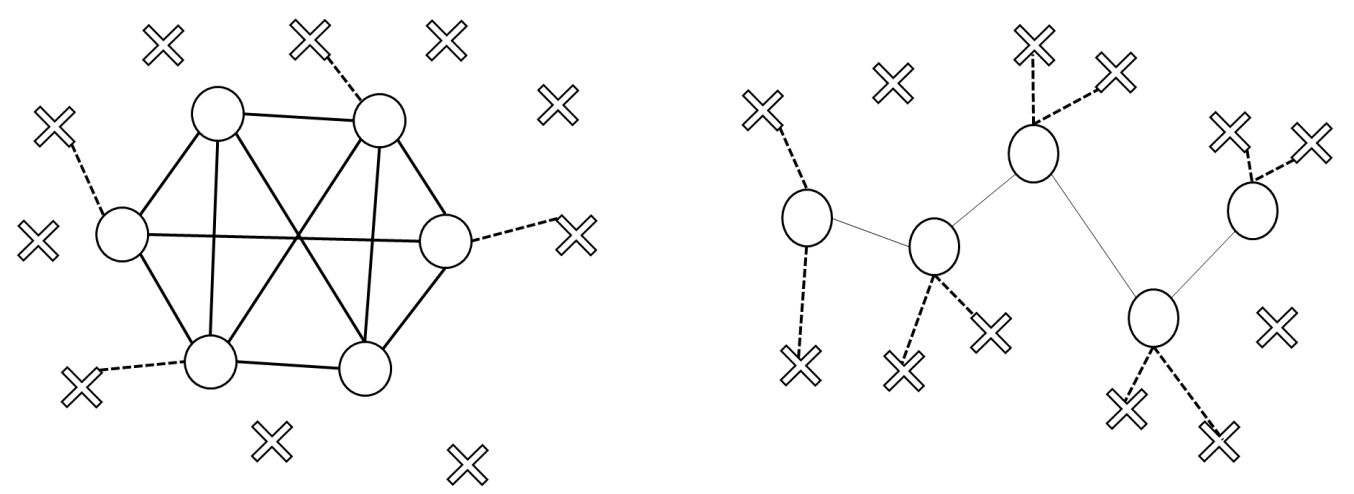

Figure 1 - Ethnic ENClaVe (LEFT) AND LOOSELY CONNECTED NETWORK (Right)

Note: These two panels depict models of migrant networks. The circles represent the migrant network; the crosses represent information sources outside the network, i.e. native people or the media. The network on the left is an ethnic enclave, with strong connections within the network but weak connections to the outside world. The network on the right is a loosely connected migrant network, with strong connections to the outside world and weak connections within the network.

unlikely to persist. The members of an enclave interact mostly with other members of the enclave, so that each member updates her beliefs based on interactions with other members. As shown by Acemoglu et al. (2010) and Bikchandani et al. (1992), misinformation is more likely to persist in such closely connected communities.

To be sure, the two network formations in Figure 1] are polar cases that illustrate the differences between migrant networks, while in reality most networks will lie somewhere in between. In the theoretical analysis, we therefore introduce a parameter $\lambda \in[0,1]$, which describes the ability of the network to aggregate accurate information.

\section{Migrant Networks and Information Flows: THEORY}

Having established why migrant networks differ in their ability to provide accurate information to future migrants, we now explain how the quality of information affects the outcome and timing of the migration decision. We first develop a two-period decision model and show that a migrant with access to a better network makes fewer mistakes in his migration decision. In a further step, we extend the model to a dynamic setting, and study how networks affect the timing of migration. 


\subsection{Intuition From a Simple Model}

In the following model, we focus on the decision of a single worker who has a connection to an already existing network. The focus on a single worker allows us to isolate the effect of a large network on one migrant from feedback effects that may arise if a whole group of people emigrates.1 ${ }^{1}$ We also assume that networks already exist and that their quality is constant over time.

Consider a potential migrant whose job at home pays a lifetime income normalized to zero, $\underline{\mathrm{w}}=0$. If she moves abroad she can either get a good job that pays him a discounted lifetime income of $w^{G}>0$ or a bad job that pays $w^{B}<0$. Before she emigrates it is uncertain which job she will actually get. If she migrates, she has to pay a sunk moving $\operatorname{cost} M$. We assume that the lifetime income of a good job is larger than the migration cost, $w^{G}>M$; otherwise migration would never be beneficial. For simplicity, we assume that the migrant is risk-neutral and maximizes expected income. She migrates if her expected income from migration minus the moving costs is greater than her income at home,

$$
\mathbb{E}(U(k))=p(k) w^{G}+(1-p(k)) w^{B}-M \geq 0,
$$

where $p(k)$ is the belief probability - the belief that she gets a good job abroad — which depends on her level of information $k$. Initially, her best guess is a commonly known probability $p_{0}$. For example, $p_{0}$ could be the fraction of previous migrants that got a good job. If she receives information from the network she will learn more about her actual odds of getting a good job, so that her best guess changes from $p_{0}$ to some other $p(k)$.

Figure 2 illustrates the worker's decision problem. In the first period $t=1$ she can decide whether to emigrate or stay. If she stays, she earns her wage at home, and she obtains additional information from the network in the second period. The signals from the network can be of two types,

$g$ : the migrant will get a good job after migration

$b$ : the migrant will get a bad job after migration.

A positive signal $g$ brings him to information set $2 A$, at which she knows that she has received a positive signal, but she does not know whether she is at the upper node and she actually gets a good job - or at the lower node. A negative signal $b$ brings him

1 See Epstein (2010) for a model of informational cascades within a group of migrants. 
to the information set $2 B$. Based on the signal she updates her beliefs from $p_{0}$ to $p(k)$, with

$$
k= \begin{cases}1 & \text { if she receives a positive signal } g \\ -1 & \text { if she receives a negative signal } b\end{cases}
$$

A positive signal increases her belief probability, while a negative signal decreases it, so that $p(1)>p_{0}>p(-1)$. The signal is truthful with probability $\lambda$, which is a function of the network quality. The more integrated the network, the higher is $\lambda$ and the more accurate is the information provided to the migrant. We assume that networks provide information to the best of their knowledge, which means that we abstract from networks spreading misinformation deliberately. Rather, networks provide noisy information about job opportunities because they have limited information themselves and simply do not know any better.

If the migrant gets a good job abroad, then the signal is positive with probability $\lambda$ and negative with probability $1-\lambda$. The opposite holds if she gets a bad job. Following our argument from Section 2, a network with more knowledge about the labour market sends a more truthful signal and spreads less misinformation. As it is unrealistic that a network has perfect knowledge and completely eliminates the migrant's uncertainty, we assume that $\lambda<1$. At the same time, $\lambda$ has to be greater than $\frac{1}{2}$ for the signal to convey a minimum level of truthfulness.2

We assume that only $p(1)$ fulfills Equation (1), so that the worker only migrates if she has received a positive signal. In the second period only two actions lead to correct decisions: in the upper node of information set $2 A$ she has received a positive signal, in which case she migrates and gets a good job; in the lower node of information set $2 B$, she has received a negative signal, so she stays while she would get a bad job if she emigrated. The remaining two actions lead to a wrong decision - a decision that makes him worse-off than she would otherwise be. In the lower node of $2 A$ she migrates despite getting a bad job abroad, while in the upper node of $2 B$ she stays although she could gain from migration. Table 1 summarises the probability distribution for the terminal nodes on the decision tree.

Clearly, the probability of making the wrong decision (rows 2 and 3 in Table 1) decreases with the signal quality $\lambda$. The higher $\lambda$, the lower is the spread of misinformation.

Proposition. 1 A potential migrant with access to a better network is less likely to make

$\overline{2}$ Otherwise, the signal would either be completely noisy $\left(\lambda=\frac{1}{2}\right)$ or it would indicate the opposite of the true state of the world $\left(\lambda<\frac{1}{2}\right)$. 


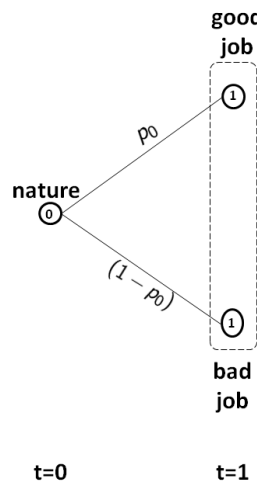

Figure 2 - Decision tree for a potential migrant: First stage (left), Second $\operatorname{STAGE}(\mathrm{RIGHT})$

Note: Decision tree with 2 stages. The panel on the left shows the first stage only, the panel on the right shows both first and second stage. In the first stage the migrant only knows the a-priori odds of getting a good job, $p_{0}$. In the second stage she receives a signal from the network which is truthful with probability $\lambda$. She migrates if the signal is positive and she stays if the signal is negative.

\begin{tabular}{llllll}
\multicolumn{2}{c}{ TABle 1} & - Probability distribution of terminal nodes \\
& Job & Signal & Action & Probability & Decision \\
\hline 1$)$ & Good & Positive & Migrate & $p_{0} \lambda$ & correct \\
2) & Good & Negative & Stay & $p_{0}(1-\lambda)$ & wrong \\
$3)$ & Bad & Positive & Migrate & $\left(1-p_{0}\right)(1-\lambda)$ & wrong \\
$4)$ & Bad & Negative & Stay & $\left(1-p_{0}\right) \lambda$ & correct \\
\hline
\end{tabular}

errors in her decision to migrate. She is more likely to stay when her prospects abroad are bad and more likely to migrate if her prospects abroad are good.

The person only emigrates if she has enough evidence that emigration is beneficial - that is, if the number of positive signals $k$ is at least as great as some threshold value, $k>k^{*}$. For simplicity we have assumed so far that one positive signal is sufficient. The result from Proposition 1, however, does not hinge on this assumption ${ }^{3}$

The aim of this model is to fix ideas, and to provide testable hypotheses based on the simplest possible framework. The model can certainly be enriched along a number of dimensions. First, we assume that the migrant is risk-neutral, so that her decision is based on expected income. It would be possible to model the objective function as a

3 It is possible to extend the model from two periods to an infinite horizon, and to express the threshold $k^{*}$ as a function of wages, moving costs, the discount factor, and the prior probability. As shown by Thijssen et al. (2004), Proposition 1 still holds in such a more general setting. 
quasi-concave utility function which allows for risk-aversion. While such a function would potentially be more realistic, it would leave the qualitative results in Table 1; more riskaverse migrants would simply require a larger number of positive signals, but Proposition 1 would still hold.

Also, the objective function does not consider changes in reference points. In our model the migrant compares the expected income in both countries, without deriving utility from a comparison with a reference group. A change in reference points - for example from the average wage in the country of origin to the average wage in the destination, may create some disutility which lowers the gains from migration (Akay et al. 2012). As with risk-aversion, the change in reference points would change the threshold number of signals, but not the error probabilites.

\subsection{Networks AND the Timing of Migration}

In a next step we extend the 2-period model from the previous section to a multi-period model, which allows us to study whether migrants with access to better networks migrate earlier than those with access to less-integrated networks.

The basic setting is the same as in the 2-period model. The migrant receives a signal from the network in every period and learns over time about her true job prospects. In every period she faces a trade-off between migrating now and waiting for the next signal. She has to weigh the cost of uncertainty today against the opportunity cost of waiting for the next signal. If she migrated today she could reap the potential benefits of migration immediately, but she would also face a higher uncertainty. If she waits one more period, she learns more about her prospects, but can only benefit from migration in the next period. We model this trade-off as an optimal stopping problem, in which the potential migrant accumulates information and postpones the migration decision until she has sufficient evidence that she will get a job that makes her better off. The sufficient amount of information depends on several parameters: the wages for good and bad jobs, moving costs, the discount factor, and the initial belief of obtaining a good job.

The number of good signals $g(t)$ evolves according to the law of motion $d g(t)=u d t$, with $g(0)=0$ and

$$
u= \begin{cases}1 & \text { with probability } \lambda \text { if } w^{G} \text { and }(1-\lambda) \text { if } w^{B} \\ 0 & \text { with probability } \lambda \text { if } w^{B} \text { and }(1-\lambda) \text { if } w^{G}\end{cases}
$$

Initially the potential migrant has a prior belief $p_{0}$. With every signal she learns more 
about her prospects and updates her beliefs by making a best guess given the available information. If she has received $n$ signals in total, of which $g$ were good, her belief probability according to Bayes' rule is,

$$
\begin{aligned}
p(n, g) & =\frac{\mathbb{P}(n, g \mid G) \mathbb{P}(G)}{\mathbb{P}(n, g \mid G) \mathbb{P}(G)+\mathbb{P}(n, g \mid B) \mathbb{P}(B)} \\
& =\frac{\lambda^{k}}{\lambda^{k}+\frac{1-p_{0}}{p_{0}}(1-\lambda)^{k}} \equiv p(k),
\end{aligned}
$$

where $P(G)=p_{0}$ and $P(B)=1-p_{0}$ are the unconditional probabilities of getting a good or a bad job. We define $k:=2 g-n$ as the excess number of good signals to bad signals 4 At a threshold $k^{*}$ the expected gain from migration in Equation (1) equals zero, so that the worker is indifferent between migrating and staying. The corresponding belief probability is $p^{*}=p\left(k^{*}\right)$. If the number of signals and the belief probability exceed $k^{*}$ and $p^{*}$, the migrant will have a higher expected income abroad, and hence emigrates. If both values are below the threshold, the migrant is better-off waiting for the next signal. Starting at time $t=0$ she will keep the option to migrate open until the number of positive signals exceeds $k^{*}$. Solving Equation (2) for $k$ and evaluating at $p^{*}=p\left(k^{*}\right)$, we obtain the threshold number of positive signals,

$$
k^{*}=\frac{\log \left(\frac{p^{*}}{1-p^{*}}\right)+\log \left(\frac{1-p_{0}}{p_{0}}\right)}{\log \left(\frac{\lambda}{1-\lambda}\right)} .
$$

The unique solution for $k^{*}$ can be obtained from dynamic programming. Formally deriving the solution is mathematically demanding, as $k^{*}$ depends on $p^{*}$, which in turn is a function of several parameters, $p^{*}=p\left(\lambda, r, w^{G}, w^{B}, M\right)$. To demonstrate the mechanics of the model we present a simple numerical example and refer the interested reader to the Appendix A.1 for a formal derivation of $k^{*}$ and $p^{*}$. We calibrate the model on the parameters listed in Table 2 and vary the quality of the network $\lambda$. After emigration the worker can either gain 20,000 or lose 10,000 compared to her job at home. The fixed moving costs are 10,000. She knows that on average $60 \%$ of all emigrants get a good job. The parameter values only serve illustrative purposes, but as we show in the comparative statics below, the qualitative results hold for a wide range of parameters.

As we can see in Figure 3 , a better network requires a lower number of positive signals.

$4 \quad$ She receives $n$ signals, of which $g$ are good and $n-g$ are bad. The difference between good and bad signals is $g-(n-g)=2 g-n$. 
TABle 2 - Parameters For the simulations

\begin{tabular}{lll}
\hline \hline$w^{G}$ & 20,000 & gain in discounted life-time income after getting a good job \\
$w^{B}$ & $-10,000$ & loss in discounted life-time income after getting a bad job \\
$M$ & 10,000 & sunk moving cost \\
$p^{0}$ & 0.6 & unconditional probability of getting a good job \\
$r$ & 0.1 & discount rate \\
$\lambda$ & 0.75 & probability of a truthful signal \\
\hline
\end{tabular}

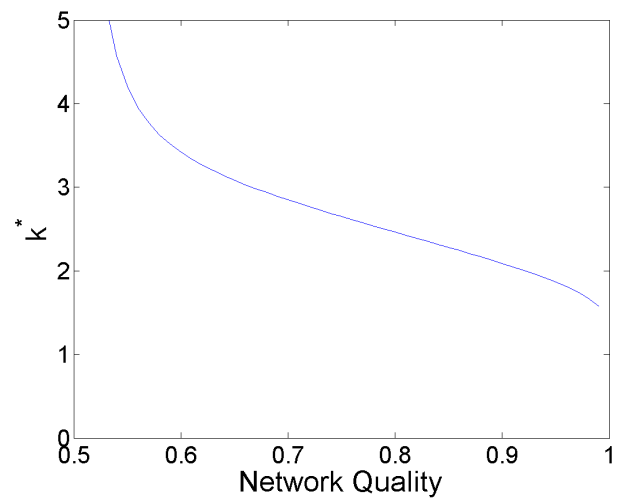

Figure 3 - Comparative Statics: CHANGe IN THE NETWORK QUALiTy $\lambda$.

Notes: The threshold belief probability $p^{*}$ increases with the network quality $\lambda$. With a higher network quality a potential migrant demands more certainty about her prospects. Right: the threshold number of positive signals $k^{*}$ decreases with the network quality $\lambda$. A better network reduces the uncertainty of migration and the potential migrant requires less positive information to emigrate.

If the signal is truthful with a probability of $55 \%$ she requires 4 positive signals in excess of negative signals, while she only requires 2 positive signals if the signal is truthful with 95\%. This result leads us to the following proposition:

Proposition. 2 A potential migrant who receives signals from a high quality network emigrates earlier.

Signals with a higher quality reduce the uncertainty more than low-quality signals. A migrant with access to a good network requires a lower number of positive signals to have sufficient evidence that emigration is beneficial.

Figure 4 shows how the threshold number of positive signals is related to other parameters. Changes in wages for good and bad jobs, $w^{G}$ and $w^{B}$, as well as the moving $\operatorname{costs} M$ work through the expected income channel. An increase in the gains from a good job, a decrease in the losses from a bad job, or a decrease in the moving costs increase the expected gains from emigration, so that a lower number of positive signals 
is sufficient. The negative relation between $k^{*}$ and the discount rate $r$ is intuitive. A low discount factor puts more weight on income in the future and leads to low opportunity costs of waiting, in which case a worker needs many positive signals to convince him to migrate early. Finally, $k^{*}$ decreases in the prior probability $p_{0}$. If a worker knows that the majority of migrants get a good job, she does not require many positive signals to be convinced. 

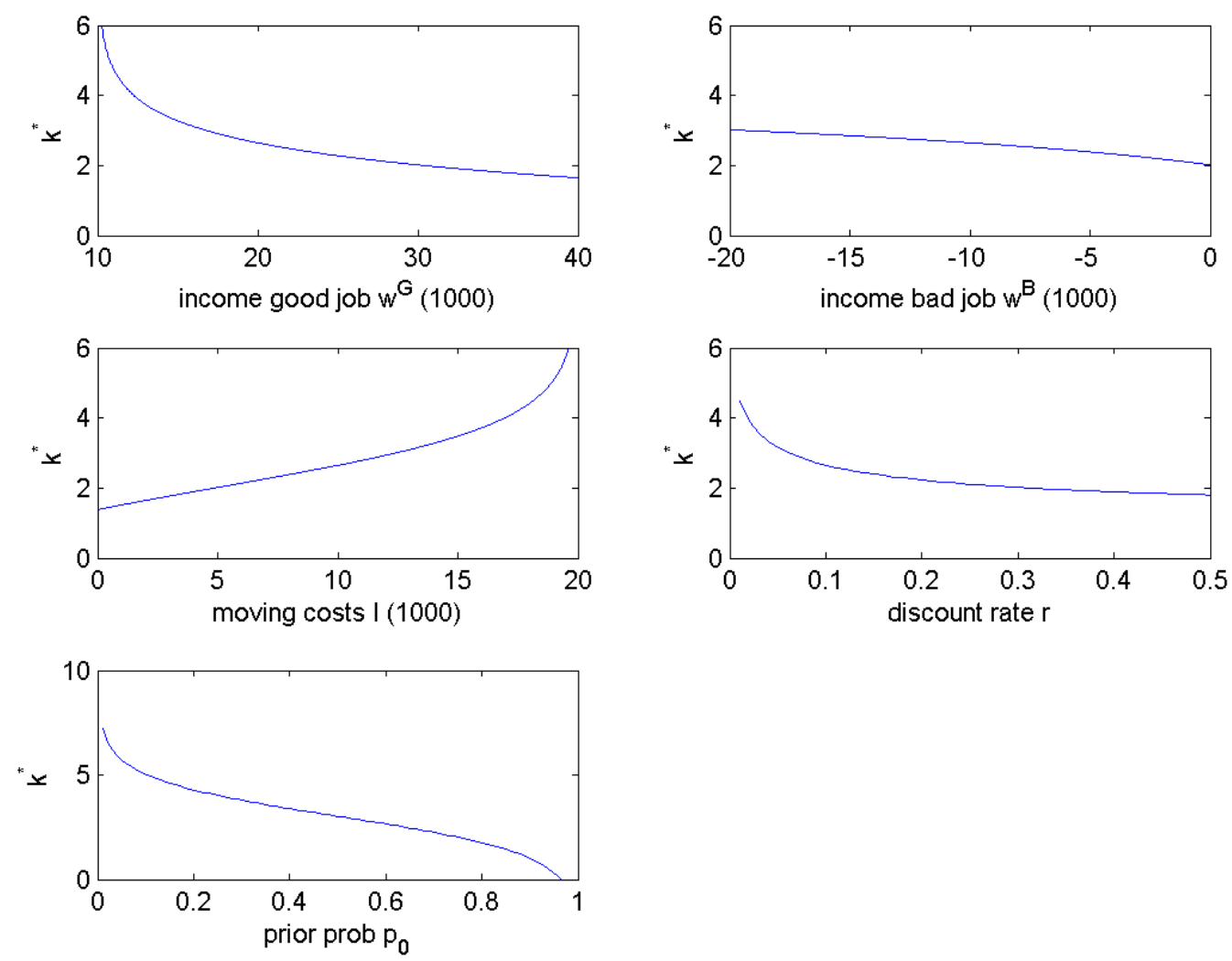

Figure 4 - Comparative Statics: VARIATION in THE MODEL PARAMETERS

Notes: The graphs show the changes in the threshold number of positive signals $k^{*}$ subject to a change in the key parameters. In each graph, the other parameters are held constant at the values stated in Table 2

\section{EMPIRICAL INVESTIGATION}

\subsection{EMPiRical Strategy}

We now turn to the empirical test of the theoretical predictions. The testable hypotheses are that migrants with access to a better network 1) are less likely to migrate if they actually get a bad job abroad, 2) are less likely to stay if they would get a good job abroad, 3) they migrate earlier, given migration is beneficial for them. In a linear specification, the hypotheses translate into the equation

$$
y=\alpha+\beta \text { network }+\boldsymbol{X}^{\prime} \boldsymbol{\gamma}+\varepsilon
$$


in which the outcome of interest $y$ - the extent to which a migrant makes an error, or the timing of migration - is explained by the network quality, individual characteristics $\boldsymbol{X}$, and factors that are unobservable to the econometrician.

In the following, we will test the first and third hypothesis, as both can be tested with data on actual migrants from the receiving countries. The second hypothesis is more difficult to test, as it requires information on workers that stay at home but that would actually gain from migration. In most poor and middle-income countries there are millions of workers who would gain from migration, but only a fraction actually has the intention to emigrate, so that it is hardly possible to spot potential migrants in a source country.

We use data on Mexican immigrants in the US, for which we can observe the characteristics of a large number of communities across the entire US. Mexicans have had a long tradition of emigrating to the US, which led to well-established Mexican networks in many US cities. Yet the settlement pattern has changed in the 1990s. While until the 1980s most Mexicans went to California, Texas, and Chicago, many Mexicans in the 1990s settled in areas that had no significant Mexican community before, such as Atlanta, Denver, Raleigh-Durham, Seattle, or Washington, D.C. (Card \& Lewis, 2007). This gradual diffusion of Mexicans across the US means that we can exploit a significant degree of variation in network characteristics across metropolitan areas and over time, and link them to the outcomes of recently arrived immigrants. Another advantage of looking at one nationality is that it reduces unobserved heterogeneity, as the network characteristics and the success of migrants probably differ less within a nationality than between different nationalities.

The estimation of Equation (4) faces two important challenges: measurement and identification. Measurement of the outcome of interest and the quality of the network is not straightforward; both variables need to be defined first. While it is possible, for example, to compute the size of the network from the number of Mexicans in a given geographic area, it is less straightforward to define factors that describe the quality of the network. Determining the potential error a migrant makes is equally challenging because of the absence of a counterfactual. As we can only observe a person either in Mexico or in the US but never in both at the same time, we cannot directly compare their situation in both countries.

To measure the quality of the network we use an assimilation index, which measures how similar Mexicans and Americans are within an area. The choice of the assimilation index as a proxy for the integration of a network follows from the well-established finding 
in the social networks literature that community members with similar characteristics are more likely to interact with each other. In our case, this means that more assimilated Mexican communities are more likely to interact with Americans, and therefore have a better knowledge about the labour market in their area, which they can pass on to future migrants. We also address the problem of a missing counterfactual by predicting counterfactual wages - the wages a migrant would have earned had she stayed in Mexico based on observable characteristics. To tackle the potential selection problems in estimating the counterfactual wage, we provide several estimates based on selection models and a matched sample.

Another important challenge is identification of the effect of networks on migration outcomes. The relationship between the network quality and the outcome of interest may be spurious if both are driven by unobserved factors. As we may not be able to control for all possible factors, we cannot be sure that the remaining variation in a simple regression would be exclusively driven by network quality. To overcome these empirical problems we rely on two instrumental variables: the change in the geographic concentration of Mexicans in the 1980s, and the location of Mexicans that arrived during the Bracero program, a guest worker program that was in place between 1942 and 1964.

In the remainder of this section we first describe the data sources and the characteristics of the sample. We then discuss in detail the measurement of the key variables and the IV strategy, before we present and discuss the results.

\subsection{Data And Descriptive Statistics}

\subsubsection{DATASETS}

The core dataset is the 2000 US census. For the calculation of counterfactual wages we also use the Mexican census of the years 1990, 2000, and we use the US census of the years 1980, 1990 to compute an index for the network quality and the instrumental variables.

The US census is conducted every year and includes the entire population. We use the 5\%-samples provided by IPUMS.5 The US census is representative at the individual and the household level and contains rich information on individual and household characteristics. Important for our analysis is information about the age at the time of immigration, birth place, current employment, education, and family situation ${ }^{6}$ We do

\footnotetext{
$5 \quad$ Ipums: Steven Ruggles, J. Trent Alexander, Katie Genadek, Ronald Goeken, Matthew B. Schroeder, and Matthew Sobek. Integrated Public Use Microdata Series: Version 5.0 [Machine-readable database]. Minneapolis: University of Minnesota, 2010.

6 The census includes both legal and illegal migrants, although it does not flag them as illegal migrants.
} 
not use earlier census rounds for the regressions, as our identification relies on historical variables, which we can only compute from 1980 onwards.

Besides the advantages mentioned above, the US census has two important limitations: it has no direct information on the network of the migrant, and the information flows between the network and the migrant prior to migration. Other datasets, for example the Mexican Migration Project, contain some information on the help of friends and family members in the migration decision, but these datasets do not contain information on the network that goes beyond family and friends, and have limited variation in networks across destinations. Another limitation of the census data is that it has no information on wages prior to migration. These would be helpful to compare the migrants' situation in Mexico and the US.7

The sample consists of Mexican immigrant men who arrived in the US no longer than 5 years before the census. We define immigrants as Mexican citizens who were born in Mexico and report in the census that they were residing in Mexico 5 years ago. The sample is restricted to Mexicans aged 18-64 who were at least 18 years old when they moved to the US, and who moved to a district with at least 20 Mexicans..$^{8}$ An outline of further restrictions to the sample can be found in Appendix C.

The restriction of the sample to recent migrants is the result of a trade-off between having a measure of lifetime success on the one hand, and having accurate information on the network and a less selective sample on the other hand. The gold standard for measuring the success of migrants would be to compare their lifetime earnings in the US with counterfactual lifetime earnings in Mexico. Unfortunately, detailed data on the entire earnings history of migrants is not available. If we used information on migrants that have been in the US for a long time from a single census round, we would not be able to reconstruct a migrant's network at the time of arrival. Moreover, as shown by Biavaschi (2012) and Campos-Vazquez \& Lara (2012), selective out-migration of more successful migrants would lead to an under-estimation of the success of migrants. With the focus on recent migrants we can only measure their short-term success, but we can obtain a more precise measure of their network, and the sample is less selective.

A potential problem regarding sample selection is the misreporting of the date of entry. Transient migrants - those who move back-and-forth between Mexico and the

\footnotetext{
Moreover, the census only includes people that stay in the US long-term; it does not include people that are on a tourist visa, or any other short-term visitors (Hanson, 2006).

$7 \quad$ See Appendix $\mathrm{B}$ for other datasets on Mexicans in the US.

8 As districts we use consistent PUMAs (public use microdata area). A cutoff of 20 is necessary for our measure of network quality. As this measure is based on a probit model at the CONSPUMA-level, a minimum number of observations is required for convergence.
} 
US - tend to report the date of their last arrival in the US, even though they had a longer history of migration to the US (Redstone \& Massey, 2004, Lubotsky, 2007). 9 To reduce the bias from misreporting the year of entry, we only include migrants who state that they lived in Mexico 5 years ago.

Another concern with data on Mexicans in the US is the undercounting of illegal migrants. The majority of Mexicans in the United States arrive as illegal immigrants and only receive their residence permit at a later stage (Massey \& Malone, 2002, Hanson, 2006). The census does not ask respondents about their legal status. Yet some illegal migrants may fear negative consequences and choose not to take part in the survey, or they may not be available for some other reason. The undercount of illegal migrants can lead to selection bias, if the least-skilled migrants are more likely to be excluded. While we are aware that undercounting may bias the results, it is important to note that the extent of undercounting has decreased significantly over the last census rounds, from 40\% undercount rate in 1980 (Borjas et al. 1991) and 15-20\% in the 1990s (Bean et al. 2001; Costanzo et al. 2002), to around 10\% in the 2000 survey (Card \& Lewis, 2007). Moreover, Chiquiar \& Hanson (2005) show that undercounting only causes minor changes to the wage distribution of Mexicans in the US, which means that there is no systematic undercount of a particular skill level.

\subsubsection{Measuring The Success of Migrants}

Next we turn to the construction of the dependent variable. To be in line with the theory, we would require a measure for an error in the migration decision - that is, a variable that indicates if a person would be better off in Mexico than in the US. We use the difference between wages in the US and in Mexico. The larger the value of this difference, the higher is the wage the US relative to Mexico, and the less likely it is that an immigrant has made an error in her decision to migrate. While the wage difference may not be as precise in measuring the error as a binary variable -1 if the wage in Mexico is larger, and 0 otherwise - it allows us to use a linear econometric model and instrumental variables.

To calculate the wage difference, we would ideally require information on earnings of the same person in the US and in Mexico. The absence of such information creates a challenge for measurement, as we can neither observe the same worker in two countries at

$9 \quad$ One reason for the misreporting among transient migrants is the ambiguous wording of the census question. In 1990 it asked when the person "came to stay", in 2000 the question was when they "came to live" (Redstone \& Massey, 2004). 
the same time, nor is the census a longitudinal dataset that contains information on wages before emigration. To obtain a Mexican wage nontheless, we predict a counterfactual wage based on observable characteristics. We attribute to every worker in the US the wage of an average Mexican worker with similar characteristics. The counterfactual wages can obviously differ from the actual wages, for example if there is selection into migration, so that there are unobservable characteristics that make migrants and stayers different from each other. We discuss the potential of selection bias in light of the recent literature on the selection of Mexicans in the US, and corroborate our predictions with a number of robustness checks.

From both the Mexican and the US census we use monthly wage data to calculate the wage difference. As Mexicans in the US and Mexico may differ in the number of working hours, we adjust wages by the number of working hours in a typical work week, and the number of weeks worked in a typical year. In addition, we convert Mexican wages into US dollars and account for differences in price levels using a PPP factor ${ }^{10}$ Initially we only include workers with a positive income in the wage regressions. Later on, we test the robustness of the wage predictions using a 2-step selection model on the full sample.

To predict the counterfactual wages, we proceed as follows. We first use the 2000 Mexican census to regress monthly wages on a vector of personal characteristics,

$$
\text { wage }=\boldsymbol{X}_{\boldsymbol{M E X}} \boldsymbol{\beta}_{\boldsymbol{M E X}}+\varepsilon,
$$

to obtain an estimate for skill prices in Mexico, $\hat{\boldsymbol{\beta}}_{\boldsymbol{M E X}} \cdot \boldsymbol{X}_{\boldsymbol{M E X} \boldsymbol{X}}$ includes a set of education dummies, a dummy for marital status, age, and age squared, as well as interactions of the education dummies with the dummy for marital status, age, and age squared. $\varepsilon$ is an error term that captures unobservable determinants of wages. The interaction terms allow us to have a separate age-earnings gradient for each education level.

Using the same characteristics for Mexicans in the US, $\boldsymbol{X}_{\boldsymbol{U}}$, we predict the counterfactual wages as

$$
\widehat{\mathrm{wage}}=\boldsymbol{X}_{\boldsymbol{U} \boldsymbol{S}} \hat{\boldsymbol{\beta}}_{\boldsymbol{M E X}} .
$$

To make both wages comparable, we convert the counterfactual wages into US dollars and adjust for differences in price levels using PPP data from the Penn World Tables.11

The difference between the actual and the counterfactual wage yields the gains from

10 See Appendix $\mathrm{C}$ for a description of the samples and the wage adjustment.

11 The PPP conversion implicitly assumes that migrants consume their entire income in the US. We will later run robustness checks, in which we assume that they consume a fraction in Mexico. 


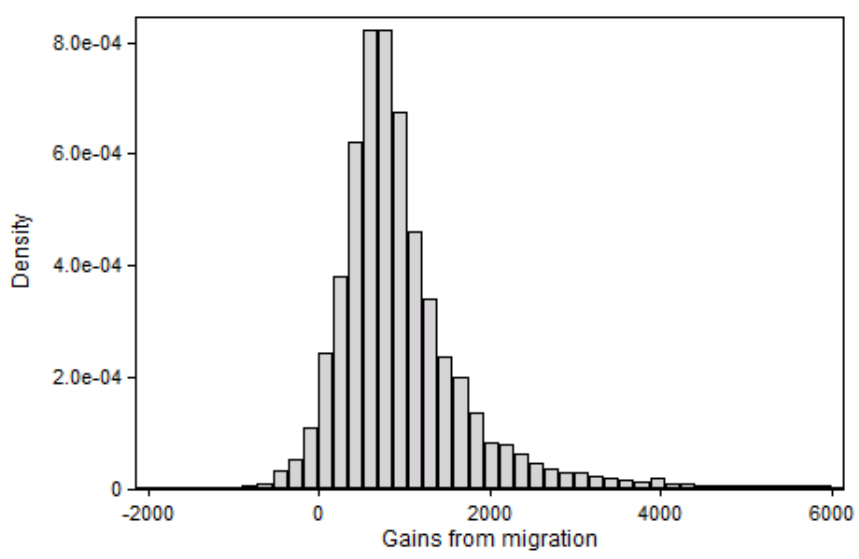

Figure 5 - Gains FROM EMIGRATION

Note: The graph shows the distribution of the losses from emigration in 2000, which is measured as the difference between the actual and counterfactual monthly income. The graphs only include workers with a positive income in the US.

emigration. Figure 5 shows the distribution of the gains for Mexicans with a positive wage income in the US. As we can see, most Mexican workers in the US are financially better off than in Mexico. The average Mexican in 2000, conditional on working, earns around 700 USD per month more in the US. Around 5\% of the distribution would be better off in Mexico, and around 25\% have a wage difference of less than 500 USD per month.

Due to unobserved factors we potentially over- or under-estimate the counterfactual wages. The prediction of counterfactual wages in Equation (6) assigns to every Mexican in the US the average wage of a worker in Mexico with the same observable characteristics. But education, age, gender, and marital status only capture some of the factors that determine wages. Unobserved factors, such as IQ, confidence, motivation, or self-selection into a certain type of firm potentially have a large impact on wages and can explain wage differentials between workers with identical observable characteristics. If migrants are positively selected - that is, if they are on average more skilled than comparable workers in Mexico - we under-estimate the counterfactual wages and undercount the number of workers who would be better off in Mexico. If migrants are negatively selected, we overestimate the counterfactual wages and the losses from emigration.

The literature on the selection of Mexican migrants has not reached a consensus on the direction of selection bias. Chiquiar \& Hanson (2005) and Orrenius \& Zavodny (2005) and Kaestner \& Malamud (2013) find that the selection of Mexican migrants occurs mostly at the center of the wage distribution. This view has been challenged by Ibarraran \& 
Lubotsky (2007), Fernández-Huertas Moraga (2011) and Ambrosini \& Peri (2012), who use longitudinal data to show that Mexican migrants are negatively selected from the wage distribution, in which case we would over-estimate the losses from emigration and classify too many immigrants as being better off in Mexico. Fernández-Huertas Moraga (2013) demonstrates that the selection pattern depends on the migrants' location in Mexico. He finds that Mexicans moving from urban areas are positively selected, while those from rural areas are negatively selected.

While our cross-sectional data does not allow us to analyze directly the direction and magnitude of the selection bias, we can get an idea of its importance by using different samples and econometric techniques for the prediction of counterfactual wages. In total, we use three different approaches. If we cannot directly observe counterfactual wages, the second best is to predict them based on Mexicans that are as similar as possible to Mexicans in the US. We first use a sample of Mexicans that are matched to similar migrants based on observable characteristics (age, gender, number of children, education). Based on a probit model we estimate for every Mexican in the initial sample the propensity of being a migrant, and only include observations in the sample whose propensity score is above the median. In another approach we restrict the sample to internal migrants, as these are more mobile and may be more similar to Mexicans in the US than the average person in the census. The third approach accounts for selection into migration, as well as for selection into employment in Mexico. The baseline predictions only include Mexicans with positive income, which can be an additional source of bias. Using the matched sample, we estimate a two-step Heckman model, with the number of children as exclusion restriction. As we show in Appendix D.1, the predicted wages are similar regardless of the method. ${ }^{12}$

The wage difference between Mexico and the US measures the success of migrants based on their economic situation in the first five years after migration. While we believe that it is a suitable measure, a few caveats about measurement are in order. First, wage differences may not be the only indicator for the success of migrants. Local amenities, available housing, and other location-specific factors may contribute to the utility of a destination. If migrants maximise utility rather than income in their location choice, then we should not be surprised if a considerable share have wage differentials close to

12 Another potential source of bias is the misreporting of educational attainment. Education is selfreported in the census, and although respondents do not benefit from misreporting, there is evidence that migrants over-report their education level (Lubotsky, 2007), for example to make them look better in front of the interviewer or other people present at the interview. Although we are aware of this problem, we see no way of circumventing it. 
zero. While non-monetary factors may play a role in location choice, recent literature has shown that a model of income maximization can explain most of the variation in location choices of both internal and international migrants (Kennan \& Walker, 2011; Grogger \& Hanson, 2011).

\subsubsection{Measuring Network Quality}

Next we turn to the measurement of networks and information flows. The theoretical model outlines a mechanism that links the social structure of the network to the quality of information about job prospects, which in turn influences the success of migrants and the timing of migration decisions. To test this mechanism empirically, we would ideally want a measure for both the social structure of the network, and the frequency and type of information flows between the network and the migrant. From the census we cannot observe these information flows. Other datasets, for example the Mexican Migration Project (MMP) have some information on information flows, but their sample size is too small to create reliable measures for networks and have sufficient variation in network characteristics across the US. Yet, building on the theory, we can proxy the quality of information by the degree of integration of the network. As outlined in Section 2, there are good reasons to believe that better integrated networks have a better knowledge about the labour markets in a given area, because they have more interaction with the world outside the network, so that false beliefs would not easily spread in such a community. As it is most likely that migrants received some information from the network they eventually moved to, we measure for each migrant the network variable using characteristics of Mexicans that already lived in the same area.

So the question is how to measure whether a migrant community is well-integrated in the area. The literature on social networks suggests statistics that measure the degree of homophily - the likelihood that a person only interacts with people of the same group (McPherson et al. 2001). An enclave would have a high degree of homophily, as its members interact mostly with each other, but not with people outside the enclave. A direct measure of homophily requires very detailed data on the connections within a community. For every member of the community we would have to know her relation to every other member. We would not be aware of the existence of such data on a large scale. And even if there was such a dataset, mapping the exact network and calculating network statistics for communities with a few thousand observations is computationally demanding.

Following this argument, we proxy the network quality with an assimilation index, 
which measures the similarity between Mexicans and Americans in a given area. If Mexicans and Americans are similar with respect to age, education, fertility, occupation, and home ownership, they most likely have more interaction with Americans, and hence the network is well-integrated and has access to more accurate knowledge about the labour market. If Mexicans and Americans in an area are very different in their behavior, there is probably little interaction between the two groups.

We calculate the assimilation index at the smallest geographic unit available in the US census, the consistent PUMA (CONSPUMA). PUMAs (Public Use Microdata Area) are small geographic units in the US census, with a population between 100,000 and 200,000 people. They do not cross state borders, and their boundaries are re-drawn with every census, so that the size of each PUMA never exceeds 200,000 people. To make PUMAs comparable over time, the US Census Bureau has introduced consistent PUMAs, which have the same boundaries from 1980 to 2010, and which are larger than the original PUMAs. As we want to calculate the assimilation index of the communities before the most recent migrants arrived, we use consistent PUMAs. To every migrant who moved to a given consistent PUMA no longer than 5 years before a census round, we assign the assimilation index of Mexicans that lived in the same area in the previous census round.

Following Vigdor (2008), we calculate the assimilation index in three steps. First, we use all Mexicans and Americans in the sample, and run for each metropolitan area separate a probit regression of a binary variable ( 1 if Mexican, 0 if US citizen) on a number of observable characteristics,

$$
P(\text { Mexican } \mid \boldsymbol{X})=F(\boldsymbol{X} \boldsymbol{\beta}) \text {. }
$$

$\boldsymbol{X}$ contains the following variables: marital status, gender, education (4 categories, see Appendix C.1), employment status, number of children, age, and home ownership. We also include the median income of the person's occupation in 1990 (variable ERSCOR90) to see whether migrants work in similar occupations compared to Americans. We use metropolitan areas for the probit regressions, as consistent PUMAs would in some cases be too small for the maximum likelihood function to converge. In the next steps, however, we obtain a distinct index for every consistent PUMA. Using the estimated coefficients $\hat{\beta}$, predict for every Mexican $i$ the probability that the person is in fact a Mexican.

$$
\hat{p}_{i}=\Phi(\boldsymbol{X} \hat{\boldsymbol{\beta}}),
$$

where $\Phi$ is the cumulative distribution function of the joint normal distribution. Let the 


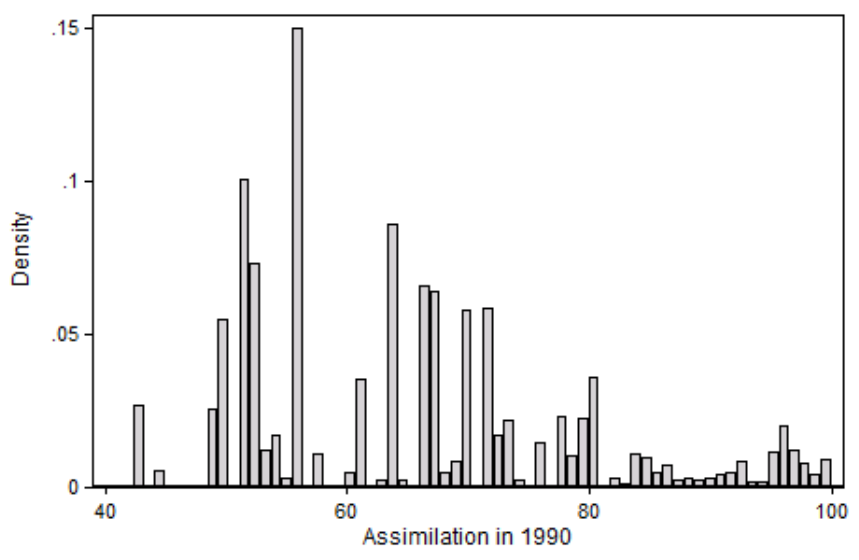

Figure 6 - Assimilation INDEX IN 1990

Note: The graph shows the distribution of the assimilation index in 1990. It is based on PUMA-level data, weighted by the number of Mexicans per PUMA.

average probability for each PUMA be $\hat{p_{m}}$.

Finally, we calculate the assimilation index for each PUMA as

$$
\operatorname{index}_{m}=100\left(1-p_{m}\right) \text {. }
$$

The sample for the calculation of the assimilation index is more restrictive than the sample used in the regressions in the next section. It consists of all Mexicans between 25 and 64 years that live in Metropolitan area with at least 20 Mexicans. To avoid the problem of reverse causality, we use the assimilation index in 1990 as a regressor that should explain the outcomes of migrants that arrived between 1995 and 2000. Figure 6 shows the distribution of the assimilation index in 1990. The density was calculated based on PUMA-level data weighted by the number of Mexicans in a PUMA, such that each bar reflects the number of Mexicans living in an area with a given assimilation index. As the figure shows, there is considerable heterogeneity in the degree of assimilation across PUMAs. The largest mass of Mexicans live in areas that have an assimilation index between 40 and 80 . Networks with assimilation indices above 80 are mostly small, although there are also a number of smaller networks that have an assimilation index lower than 80 .

\subsubsection{Descriptive Statistics}

Table 3 displays the descriptive statistics for the US census in 2000. Panel A shows the aggregate statistics at the PUMA-level, while panel B shows the individual-level statistics 
TABlE 3 - SumMARY STATISTICS

\begin{tabular}{lrrrrrr}
\hline \hline & N & mean & sd & median & min & max \\
\hline A. Aggregate data & & & & & & \\
Income difference US-Mex & 324 & 748.54 & 537.24 & 690.21 & -690.38 & 3729.80 \\
Assimiliation 1990 & 203 & 85 & 16 & 92 & 42 & 100 \\
Share of Mexicans (\%) & 324 & 3.1 & 5.5 & 0.9 & 0.0 & 34.8 \\
Nr of Mexicans (in 1000) & 324 & 13.4 & 45.5 & 1.7 & 0.0 & 555.0 \\
Change in concentration & 165 & 1.4 & 2.2 & 0.4 & -0.6 & 11.1 \\
Share of braceros (\%) & 324 & 0.14 & 0.37 & 0.02 & 0.00 & 3.85 \\
\hline B. Individual-level data & & & & & & \\
Income difference US-Mex & 21,762 & 695 & 1144 & 625 & $-1,425$ & 13,558 \\
Age at immigration & 22,465 & 26.7 & 8.7 & 24.0 & 18.0 & 64.0 \\
Assimiliation 1990 & 20,787 & 73 & 16 & 70 & 42 & 100 \\
High-school dropouts & 22,465 & 0.14 & & & & \\
Lower secondary & 22,465 & 0.49 & & & & \\
Upper secondary & 22,465 & 0.33 & & & & \\
College & 22,465 & 0.04 & & & & \\
Age & 22,465 & 28.6 & 8.7 & 26 & 18 & 64 \\
Married & 22,465 & 0.48 & 0.50 & 0.00 & 0.00 & 1.00 \\
\hline
\end{tabular}

Note: Aggregate statistics are computed at the CONSPUMA-level, conditional on at least one Mexican living in the area. Change in concentration is the percentage-point change in the concentration of Mexicans between 1980 and 1990. The share of Braceros is the share of Mexicans in the population of a CONSPUMA that immigrated between 1942 and 1964. Individual-level data is based on men only. 
of the sample. In the regressions to follow, we will use both aggregate and individual data.

The aggregate variables in panel A are computed conditional on at least one Mexican living there. The distribution of Mexicans across the US is heavily skewed, with a large number of small communities, and a small number of large communities. The median share of Mexicans in a PUMA is $0.9 \%$ and the median number is 1,700 , while the largest number of Mexicans in a PUMA is more than 500,000 (a CONSPUMA within Los Angeles), and the area with the largest concentration has 35\% Mexicans (McAllenEdinburg-Pharr-Mission, TX).

Panel B displays the characteristics of immigrants that recently arrived in the US. Most immigrants come to the US in their early 20s, and the vast majority has a lower secondary education or less, while there are very few Mexicans with a college education. The median Mexican moved to a community with an assimilation index of 70 . For most immigrants, migration pays off; on average, Mexicans in the US earn around 700 USD more than they would earn in Mexico, although there is a large degree of heterogeneity in the income difference.

\subsection{IDENTIFICATION}

To estimate the causal effect of network quality on the success and timing of migrants, one would ideally want to randomly assign new immigrants to different types of networks and observe the differences in the outcome of interest after they have migrated. Given that such an experiment is not available for Mexicans in the US, an alternative approach would be to find exogenous variation in the quality of networks that is unrelated to other factors that may affect the outcome of interest. In the absence of a clean quasi-experiment - for example a change in migration policies - , we rely on instrumental variables that affect the assimilation of a local Mexican community, while it has no direct effect on the outcomes of interest.

$$
y_{2000}=\alpha+\beta \operatorname{assim}_{1990}+\gamma \text { avwage }_{2000}+\varepsilon,
$$

The estimating equation $(10)$ describes the linear relationship between the assimilation of Mexicans in a given CONSPUMA in 1990, and the difference between monthly income in the US and the counterfactual in Mexico, measured in 2000 for immigrants that moved to the CONSPUMA after 1995. avwage $_{2000}$ is the average wage of US workers in a CONSPUMA, which controls for differences in wage and price levels across the US. $\varepsilon$ 
is an error term.

In this regression, the assimilation index is potentially endogenous, in which case the estimate for $\beta$ would be biased. One source of endogeneity is reverse causality. Successful migrants may settle in areas in which they are similar to Americans, in which case we would observe a positive correlation between assimilation and the income difference, but causality would run from income to assimilation. In our case, however, reverse causality does not threaten identification, as the assimilation is measured 10 years before the outcome of interest, so that pre-determines the success of migrants that subsequently move to the area. More problematic for identification are unobserved factors that may drive the correlation between both variables. For example, if local amenities have attracted migrants with higher unobserved skills in the past and in the present, $\beta$ would be positive, but this relationship is not causal.

To disentangle the effect of network quality on the success of migrants from the influence of unobserved factors, we use two instrumental variables that predict the assimilation index in 1990 but have no impact on current outcomes of immigrants. Both instruments exploit the settlement patterns of earlier Mexican immigrants.

INSTRUMENT I: CHANGE IN THE CONCENTRATION OF MEXICANS The first instrument is the change in the concentration of Mexicans in a CONSPUMA between 1980 and 1990. Areas in which the density of Mexicans increases become more enclaved, and hence less assimilated. The graph on the left in Figure 7 confirms this negative relationship. The slope coefficient of the fitted regression line is highly significant, and the change in concentration explains $73 \%$ of the variation in the assimilation index. To be valid as an instrument, the change in immigrant concentration in the past should not have any direct effect on the success and timing of migration today, besides the indirect effect through the quality of the network. While this assumption cannot be tested, it is plausible to assume that changes in the concentration of Mexicans in an area more than 10 years ago have no direct impact on labour market outcomes today. If past settlement had a strong direct effect on the success of migrants, we would expect a strong persistence in the success of new immigrants within an area over time. However, we cannot find this persistence in the data. The correlation between wage differentials in 1990 and 2000 is 0.06 .

INSTRUMENT II: SHARE OF BRACERO IMMIGRANTS As a second instrument we use the share of Bracero immigrants in a CONSPUMA. The Bracero Program was a 

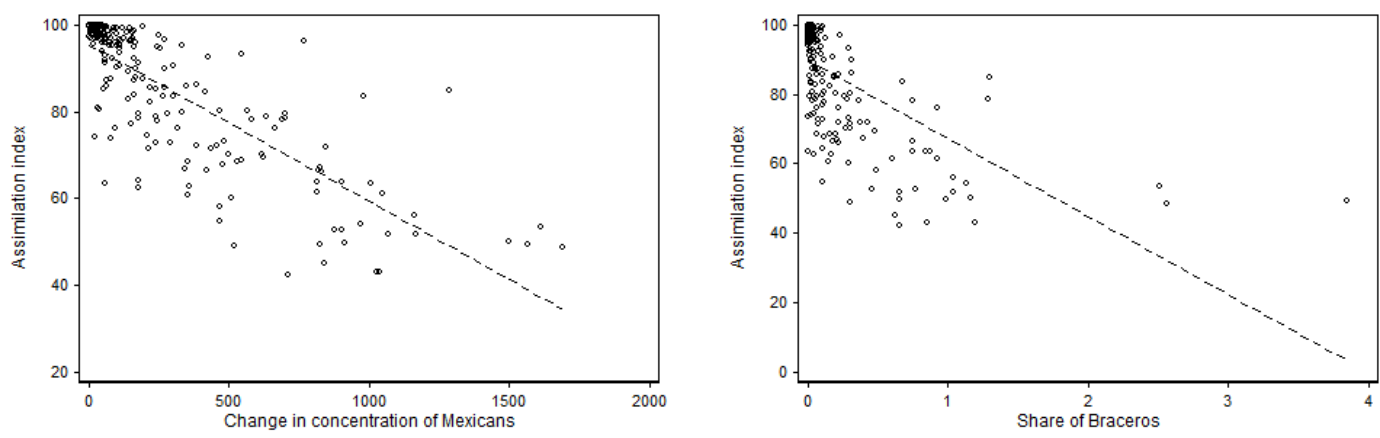

Figure 7 - First stage: Correlation instrument With assimilation.

Note: The regression line on the left is assim $=93(0.79)-4.79(0.15)$ change in concentration; $R^{2}=0.73$. On the right: assim $=89.7(0.97)-22.5(1.95)$ share of braceros; $R^{2}=0.39$.

temporary migration program that allowed Mexicans to take up temporary agricultural work in the US. Over the duration of the program, from 1942 to 1964, around 4.5 million Mexican workers came to the US. As shown by Massey \& Liang (1989), many of these workers took repeated trips to the US, and eventually settled there. We calculate the number of Bracero migrants as the number of Mexicans in a CONSPUMA in the 2000 census who arrived in the US between 1942 and 1964, and divide this number by the total population to obtain the share.

The presence of Braceros has a strong negative association with assimilation in 1990, as the graph on the right in Figure 7 shows. The Braceros, who were predominantly lowskilled, were different from Americans to begin with, and this difference carried through to Mexicans living there in 1990. Even though the share of Braceros is low in most CONSPUMAs, it explains 39\% of the variation in the assimilation index in 1990.

The identifying assumption behind the Bracero instrument follows the typical network argument in the migration literature. An initial immigration shock triggered a process of subsequent migration of similar workers, leading to the strong first-stage correlation. On the other hand, regions typically adjust to labor supply shocks within 10 years (Blanchard et al., 1992), which means that we should be safe assuming that immigration into local labor markets in the 1950s has been fully absorbed by 2000 and should not determine the economic prospects of Mexicans living there in 2000, other than through networks that have been established over time. 


\subsection{Results}

\subsubsection{NETWORKS AND THE SUCCESS OF RECENT IMMIGRANTS}

Equipped with the two instrumental variables, we now estimate the impact of network quality on the success of recent migrants. We first present the results of aggregate regressions at the CONSPUMA-level. Table 4 shows the estimation results for Equation (10). Because Mexican communities differ considerably in size, and we want to give each Mexican equal weight, all regressions are weighted by the number of Mexicans per CONSPUMA. To make results comparable across columns, we restrict the sample to those CONSPUMAs for which we are able to compute the change in concentration between 1980 and 1990, that is, those with at least one Mexican in 1980.

TAble 4 - Aggregate Regressions: Networks and the sucCess of ReCEnt MIGRANTS

Dependent variable: income difference US-Mexico

\begin{tabular}{lcccc}
\hline \hline & $(1)$ & $(2)$ & $(3)$ & $(4)$ \\
& OLS & 2SLS & 2SLS & 2SLS \\
\hline Assim 1990 & $5.623^{* * *}$ & $6.743^{* * *}$ & $4.931^{*}$ & $6.469^{* * *}$ \\
& {$[0.936]$} & {$[1.026]$} & {$[2.802]$} & {$[1.067]$} \\
& & & & \\
\hline First stage coefficients & & & & \\
$\Delta$ Concentration Mex. & & $-4.191^{* * *}$ & & $-4.417^{* * *}$ \\
& & {$[0.467]$} & & {$[1.237]$} \\
Braceros & & & $-12.138^{* * *}$ & $-3.526^{* * *}$ \\
& & & {$[3.359]$} & {$[0.527]$} \\
\hline F-stat & & & 13.1 & 138.7 \\
P-value (Sargan) & 158 & 158 & 158 & 0.3 \\
$N$ & & & & 158 \\
\hline \hline
\end{tabular}

Note: The table displays regression results at the conspuma-level. Dependent variable is monthly income in the US minus monthly income in Mexico in USD adjusted for PPP differences. All regressions are weighted by the number of Mexicans in a conspuma, and include a control for the average US wages. Standard errors in brackets. ${ }^{*} \mathrm{p}<0.10,{ }^{* *} \mathrm{p}<0.05,{ }^{* * *} \mathrm{p}<0.01$

The results show that network quality has a strong positive impact on the success of migrants. The OLS results suggest that an increase in the assimilation index by $1 \%$ increases the monthly income difference between the US and Mexico by 5.6 USD. In terms of standard deviations, a one standard deviation increase in the assimilation index increases the income difference by 90 USD, or $16 \%$ of a standard deviation. 
The instrumental variable estimates are shown in Columns (2)-(4). In all specifications the point estimates lie within the same range, with a mid-point of around 5.5. In the first stage, both instruments have the expected sign and are sufficiently strong. A larger change in the concentration of Mexicans between 1980 and 1990 is associated with a lower degree of assimilation in 1990. Similarly, a higher share of Bracero immigrants is associated with less assimilation. The F-Statistics are above the weak instrument threshold of 10, although the change in concentration instrument has more explanatory power in the first stage than the Bracero instrument. The Sargan test does not reject the null hypothesis of overidentifying restrictions, which is an indicator of the validity of our instruments.

As a further robustness check, we estimate Equation (10) using individual-level data. The aggregate data could mask a considerable level of heterogeneity, as suggested by the difference in the summary statistics between aggregate and individual-level data in Table 3. The maximum income difference, for example, is 3 times as high in the individuallevel data, while the mean and median lie close together. A problem with the calculation of the income difference is the presence of zeros in the US wage data. Of the 18,379 observations used in the base regressions, around one quarter report an income of zero in the US, which would downward-bias the measured income difference. In the individuallevel regressions we estimate the same model for the full sample and for a sample that only includes Mexican men who have a positive income in the US.

Table 5 displays the individual-level estimates. In all regressions we control for the average wage of US workers at the CONSPUMA-level, as well as for 3 education-group dummies, a quadratic in age, and marital status. Because the assimilation index is measured at the CONSPUMA-level, we report standard errors clustered by CONSPUMA in brackets. We also report bootstrapped and clustered standard errors in parentheses, acknowledging that the assimilation index has been estimated from a probit model.

The estimates based on the full sample, displayed in Panel A, are of the same magnitude as the results based on aggregate data. As before, the instruments are sufficiently strong, and the overidentification test indicates the absence of endogeneity in the instruments. A comparison with the results in Panel B, which are based on the restricted sample, show that zero US incomes do not significantly change the results.

A potential threat to identification is the role of the size of the network. More assimilated networks are on average smaller, so that the assimilation index could pick up the impact of network size rather than network quality. To assess whether size is indeed a driving factor, we re-estimate the model, controlling for the number of Mexicans in 2000 
TABle 5 - Aggregate Regressions: Networks And the SUCCESS OF RECEnT MIGRANTS

Dependent variable: income difference US-Mexico

\begin{tabular}{|c|c|c|c|c|c|}
\hline \multicolumn{6}{|l|}{ A. full sample } \\
\hline & $(1)$ & $(2)$ & (3) & (4) & $(5)$ \\
\hline & OLS & 2SLS & 2SLS & 2SLS & 2SLS \\
\hline \multirow[t]{3}{*}{ Assim 1990} & $4.858^{* * *}$ & $5.646^{* * *}$ & $5.301^{* * *}$ & $5.606^{* * *}$ & $6.103^{* * *}$ \\
\hline & {$[0.793]$} & {$[0.766]$} & {$[1.168]$} & {$[0.771]$} & {$[0.986]$} \\
\hline & $(0.835)$ & $(0.844)$ & $(1.249)$ & $(0.889)$ & $(1.110)$ \\
\hline \multirow[t]{2}{*}{$\mathrm{Nr}$ of Mexicans } & & & & & 0.006 \\
\hline & & & & & {$[0.006]$} \\
\hline \multicolumn{6}{|l|}{ First stage coefficients } \\
\hline \multirow[t]{2}{*}{$\Delta$ Concentration Mex. } & & $-4.817^{* * *}$ & & $-4.578^{* * *}$ & $-4.544^{* * *}$ \\
\hline & & {$[0.485]$} & & [0.162] & [0.160] \\
\hline \multirow[t]{2}{*}{ Braceros } & & & $-20.533^{* * *}$ & $-4.328^{* * *}$ & $-4.137^{* * *}$ \\
\hline & & & {$[0.574]$} & [0.048] & [0.063] \\
\hline F-stat & & 161.2 & 18.1 & 118.2 & 57.8 \\
\hline P-value (Sargan) & & & & 0.63 & 0.57 \\
\hline$N$ & 18,379 & 18,379 & 18,379 & 18,379 & 18,379 \\
\hline \multicolumn{6}{|c|}{ B. only positive incomes } \\
\hline \multirow[t]{3}{*}{ Assim 1990} & $5.544^{* * *}$ & $5.764^{* * *}$ & $5.162^{* * *}$ & $5.696^{* * *}$ & $6.398^{* * *}$ \\
\hline & {$[0.863]$} & {$[0.855]$} & {$[1.041]$} & {$[0.850]$} & [0.882] \\
\hline & $(0.921)$ & $(0.865)$ & $(1.110)$ & $(0.928)$ & $(0.993)$ \\
\hline \multirow[t]{2}{*}{$\mathrm{Nr}$ of Mexicans } & & & & & 0.009 \\
\hline & & & & & {$[0.011]$} \\
\hline \multicolumn{6}{|l|}{ First stage coefficients } \\
\hline \multirow[t]{2}{*}{$\Delta$ Concentration Mex. } & & $-4.855^{* * *}$ & & $-4.372^{* * *}$ & $-4.203^{* * *}$ \\
\hline & & [0.053] & & [0.052] & [0.070] \\
\hline \multirow[t]{2}{*}{ Braceros } & & & $-20.420^{* * *}$ & $-4.498^{* * *}$ & $-4.473^{* * *}$ \\
\hline & & & [0.631] & {$[0.174]$} & [0.172] \\
\hline F-stat & & 174.3 & 16.2 & 124.4 & 62.6 \\
\hline P-value (Sargan) & & & & 0.45 & 0.39 \\
\hline$N$ & 13,827 & 13,827 & 13,827 & 13,827 & 13,827 \\
\hline
\end{tabular}

Note: The table displays individual-level regression results. Dependent variable is monthly income in the US minus monthly income in Mexico in USD adjusted for PPP differences. All regressions are include a control for the average US wages at the CONSPUMA-level, as well as individual-level controls for education, a quadratic in age, and marital status. Standard errors, displayed in brackets, are clustered at the conspuma-level; bootstrapped standard errors with 500 replications in parenthese. Significance levels refer to standard errors in brackets: ${ }^{*} \mathrm{p}<0.10,{ }^{* *} \mathrm{p}<0.05,{ }^{* * *} \mathrm{p}<0.01$ 
in a CONSPUMA in both stages of the IV estimation. As can be seen in Column (5), both the point estimates, and the first stage coefficients are of similar size and significance. Moreover, the coefficient of the number of Mexicans is statistically insignificant.

In sum, both the aggregate and individual-level regression confirm the theoretical prediction that better networks - as measured by a higher degree of assimilation increase the likelihood of a successful migration. The estimated effect is both statistically and economically significant. The income difference between being associated with a network at the 25th and a network at the 75 th percentile of the assimilation index is 120USD in monthly income. Moreover, the results hold if we control for the size of the network, and if we exclude Mexicans with zero income in the US.

\subsubsection{NeTWORKS AND THE TIMING OF MIGRATION}

Next we test the theoretical prediction that migrants with access to a better network migrate earlier. The intuition behind this prediction is that migrants with access to better networks receive more accurate information, and need fewer signals to be convinced that they should migrate. Consequently, they should migrate earlier than migrants who receive information from a less integrated network. While we do not have longitudinal data, and no direct data on information flows between a potential migrant and her network, we can test the theoretical prediction in a reduced-form relationship between the assimilation index and the age at immigration.

We estimate the model

$$
\text { age at immigration } \text { im,2000 }=\alpha+\beta \operatorname{assim}_{c, 1990}+\varepsilon_{c},
$$

both with aggregate and with individual-level data. In the individual-level data we also control for three education dummies, with high-school dropouts being the base category. Controlling for education is important, as less-educated people might be able to leave earlier because they finished their education earlier. As before, standard errors are clustered at the CONSPUMA-level, and we instrument the assimilation index with previous changes in the concentration of Mexicans and the share of Braceros. Table 6 shows the results.

In 5 out of 6 specifications, the results are virtually zero. Not even a large increase in the assimilation index would predict a change in the timing of migration, so that our theoretical prediction has to be rejected. Despite the clear intuition of the theoretical model, as to why migrants with access to better information emigrate earlier, the data 
TABle 6 - AgGregate REgREssions: Network QUALity AND THE TIMING OF MIGRATION

Dependent variable: Age at immigration

\begin{tabular}{|c|c|c|c|c|c|c|}
\hline & \multicolumn{3}{|c|}{ Aggregate regressions } & \multicolumn{3}{|c|}{ Individual regressions } \\
\hline & (1) & $(2)$ & $(3)$ & (4) & (5) & (6) \\
\hline & OLS & 2SLS & 2SLS & OLS & 2SLS & 2SLS \\
\hline \multirow[t]{3}{*}{ Assim. 1990} & -0.006 & 0.010 & $-0.149^{* *}$ & 0.002 & 0.006 & $-0.050^{*}$ \\
\hline & {$[0.017]$} & {$[0.011]$} & {$[0.061]$} & {$[0.007]$} & {$[0.008]$} & {$[0.030]$} \\
\hline & & & & $(0.031)$ & $(0.009)$ & $(0.017)$ \\
\hline \multicolumn{7}{|l|}{ First stage coefficients } \\
\hline$\Delta$ Concentration Mex. & & $-4.191^{* * *}$ & & & $-4.809^{* * *}$ & \\
\hline \multirow{2}{*}{ Braceros } & & & $-12.138^{* * *}$ & & & $-19.068^{* * *}$ \\
\hline & & & [3.359] & & & {$[0.550]$} \\
\hline F-stat & & 80.5 & 13.1 & & 162.9 & 15.7 \\
\hline$N$ & 158 & 158 & 158 & 18,986 & 18,986 & 18,986 \\
\hline
\end{tabular}

Note: Columns (1)-(3) display aggregate regressions at the conspuma-level. Regressions are weighted by the number of Mexicans in a conspuma. Standard errors are displayed in brackets. Columns (4)-(6) display the results of individual-level regressions. Standard errors, clustered at the conspuma-level, are shown in brackets, bootstrapped standard errors with 500 replications in parentheses. Significance stars refer to first row of standard errors: ${ }^{*} \mathrm{p}<0.10,{ }^{* *} \mathrm{p}<0.05,{ }^{* * *} \mathrm{p}<0.01$. 
reject this mechanism.

One explanation for the absence of an effect is that migrants base the timing of their decision on factors other than networks. According to this interpretation, networks may well influence if people migrate at all, but conditional on migrating, they have no further influence on its timing. Factors like family situation or financial constraints may be more important for the timing than the accuracy of information about job prospects.

\section{CONCLUSION}

Around the world, migrant communities differ not only in their size but also in their degree of integration in the host society. In this paper, we study how the integration of existing migrant communities affects the migration decisions and economic outcomes of future migrants. Following the literature on social networks, we argue that more integrated networks have a better knowledge of the labour market in the destination, and therefore give more accurate information about job opportunities to future migrants. We first explore this mechanism in a decision model with imperfect signalling, which predicts that migrants who receive information from better-integrated networks make fewer errors in their migration decisions, and they migrate earlier.

Using data on recent Mexican immigrants in the US, we test these predictions empirically. The focus on Mexico allows us to exploit a significant variation in the size and social structure of migrant communities across the United States. We measure the two variables of interest - the likelihood of making an error, and the quality of the migrant network - using the wage difference between the US and Mexico, and an assimilation index which measures the similarity of Mexicans and Americans in an area with respect to a large number of observable characteristics. To overcome omitted variable bias, we instrument the assimilation index with past changes in the diffusion of Mexicans across the US, and with past settlement patterns of low-skilled Mexicans that came to the US during the Bracero program. Our results confirm the first hypothesis. Migrants with access to a better-integrated network had a significantly larger wage differential between the US and Mexico, and hence were less likely to make an error in their migration decision. We find no evidence, however, for the second hypothesis. The quality of networks has no effect on the timing of migration decisions.

With its focus on the quality of networks, this paper offers a new perspective on the role of networks in international migration. While the previous literature has proxied the strength of migrant networks through their size, we show, both theoretically and 
empirically, that the quality of networks has a sizable impact on the economic outcomes of migrant.

In addition, the theoretical model and the empirical findings offer new insights for the study of social networks in general. Most of the empirical literature focuses on the impact of the architecture of social networks on individual members of the network. Our paper shows that the social structure of networks also affects people outside the network - in our case potential migrants who still live in the country of origin - through the network's ability to aggregate information. If more integrated communities have better knowledge and are able to provide more accurate information, this benefits the recipients of the information.

The empirical analysis, while informative, is constrained by the available data on networks and information flows. The assimilation of migrants in a given area is a first step towards mapping the social structure of immigrant communities, but more detailed data on connections between immigrants would permit a more accurate description of the integration of these communities. Also, in our data we do not directly observe information flows, which is why we assume that migrants received information from an existing community in the destination. More detailed data on the type, frequency, and content of information flows would give important further insights into the exact channels through which information flows affect migrant outcomes. 


\section{REFERENCES}

Acemoglu, Daron, Ozdaglar, Asuman, \& Gheibi, Ali Parandeh. 2010. Spread of (Mis)Information in Social Networks. Games and Economic Behavior, 70, 194-227.

Akay, Alpaslan, Bargain, Olivier, \& Zimmermann, Klaus F. 2012. Relative Concerns of Rural-to-Urban Migrants in China. Journal of Economic Behavior and Organization, 81, 421-441.

Alatas, Vivi, Banerjee, Abhijit, Chandrasekhar, Arun G., Hanna, Rema, \& Olken, Benjamin A. 2012. Network Structure and the Aggregation of Information: Theory and Evidence from Indonesia. NBER Working Paper, 18351.

Ambrosini, J. William, \& Peri, Giovanni. 2012. The Determinants and the Selection of Mexico-US Migrants. The World Economy, 35(2), 111-151.

Amuedo-Dorantes, Catalina, \& Mundra, Kusum. 2007. Social Networks and their Impact on the Earnings of Mexican Migrants. Demography, 44(4), 849-863.

Andersson, Fredrik, Burgess, Simon, \& Lane, Julia. 2009. Do as the Neighbors Do: The Impact of Social Networks on Immigrant Employment. IZA Discussion Paper, 4423.

Batista, Catia, \& NArciso, Gaia. 2013. Migration and Information Flows: Evidence from a Field Experiment among Immigrants in Ireland. CReAM Discussion Paper, 31.

Bauer, Thomas, Epstein, Gil S., \& Gang, Ira N. 2005. Enclaves, Language, and the Location Choice of Migrants. Journal of Population Economics, 18, 649-662.

Bauer, Thomas, Epstein, Gil S., \& Gang, Ira N. 2007. Herd Effects or Migration Networks? The Location Choice of Mexican Immigrants in the U.S. Research in Labor Economics, 26, 199-229.

Bean, Frank D., Corona, Rodolfo, Tuiran, Rodolfo, Woodrow-lafield, Karen A., \& van Hook, Jennifer. 2001. Circular, Invisible, and Ambiguous Migrants: Components of Difference in Estimates of the Number of Unauthorized Mexican Migrants in the United States. Demography, 38(3), 411-422.

Beckhusen, Julia, Florax, Raymond J.G.M., de Graaff, Thomas, Poot, JACQUES, \& WALDORF, BRIGITTE. 2012. Living and Working in Ethnic Enclaves: 
Language Proficiency of Immigrants in U.S. Metropolitan Areas. IZA Discussion Paper, 6363.

Beine, Michel, Docquier, Frédéric, \& Özden, ÇaĞLar. 2010. Diasporas. Journal of Development Economics, 95(1), 30-41.

Beine, Michel, Docquier, Frédéric, \& Özden, ÇaĞLar. 2011. Dissecting Network Externalities in International Migration. CESifo Discussion Paper, 3333.

Bertoli, Simone. 2010. The Informational Structure of Migration Decision and Migrants Selection. Economics Letters, 108, 89-92.

Biavaschi, Costanza. 2012. Recovering the Counterfactual Wage Distribution with Selective Return Migration. IZA Discussion Paper, 6795.

Bikchandani, Sushil, Hirshleifer, David, \& Welch, Ivo. 1992. A Theory of Fads, Fashion, Custom and Cultural Change as Informational Cascades. Journal of Political Economy, 100(5), 992-1027.

Blanchard, Olivier J., Katz, Lawrence F., Hall, Robert E., \& Eichengreen, BARRY. 1992. Regional Evolutions. Brookings Papers on Economic Activity, 1, 1-75.

Borjas, George J. 1995. Ethnicity, Neighborhoods and Human-Capital Externalities. The American Economic Review, 85(3), 365-390.

Borjas, George J., Freeman, Richard B., \& Lang, Kevin. 1991. Undocumented Mexican-born Workers in the United States: How Many, How Permanent? Chap. 2, pages 77-100 of: ABowd, John M., \& FreEman, Richard B. (eds), Immigration, Trade and the Labor Market. University of Chicago Press.

Burda, Michael C. 1995. Migration and the Option Value of Waiting. The Economic and Social Review, 27(1), 1-19.

Campos-Vazquez, Raymundo M, \& Lara, Jaime. 2012. Self-selection Patterns among Return Migrants: Mexico 1990-2010. IZA Journal of Migration, 1(8).

Card, David, \& Lewis, Ethan G. 2007. The Diffusion of Mexican Immigrants During the 1990s: Explanations and Impacts. Chap. 6, pages 193-228 of: BorJAS, GeOrGe J. (ed), Mexican Immigration to the United States. University Of Chicago Press. 
Carrington, William J., Detragiache, Enrica, \& Vishwanath, Tara. 1996. Migration with Endogenous Moving Costs. The American Economic Review, 86(4), 909-930.

Chiquiar, Daniel, \& Hanson, Gordon H. 2005. International Migration, SelfSelection and the Distribution of Wages: Evidence from Mexico and the United States. Journal of Political Economy, 113(2).

Costanzo, Joseph M., Davis, Cynthia, Irazi, Caribert, Goodkind, Daniel, \& RAmirez, RoBerto. 2002. Evaluating Components of International Migration: The Residual Foreign Born. US Census Bureau Population Division Working Paper, 61.

Currarini, Sergio, Jackson, Matthew O., \& Pin, Paolo. 2009. An Economic Model of Friendship: Homophily, Minorities and Segregation. Econometrica, 77(4), 1003-1045.

Eagle, Nathan, Macy, Michael, \& Claxton, Rob. 2010. Network Diversity and Economic Development. Science, 328, 1029-1031.

Edin, Per-Anders, Frederiksson, Peter, \& Aslund, Olof. 2003. Ethnic Enclaves and the Economic Success if Immigrants - Evidence from a Natural Experiment. The Quarterly Journal of Economics, 118(1), 329-357.

Epstein, Gil S. 2010. Informational Cascades and the Decision to Migrate. Chap. 2, pages 25-44 of: Epstein, GiL. S., \& GAng, IrA N. (eds), Migration and Culture. Emerald Group Publishing Limited.

FARré, Lidia, \& FAsani, Francesco. 2013. Media Exposure and Internal Migration: Evidence from Indonesia. Journal of Development Economics, 102(C), 48-61.

Fernández-Huertas Moraga, Jesús. 2011. New Evidence on Emigrant Selection. The Review of Economics and Statistics, 93(1), 72-96.

Fernández-Huertas Moraga, Jesús. 2013. Understanding Different Migrant Selection Patterns in Rural and Urban Mexico. Journal of Development Economics, forthcoming.

Fogli, Alessandra, \& Veldkamp, Laura. 2012. Germs, Social Networks, and Growth. NYU Working Paper. 
Golub, Benjamin, \& Jackson, Matthew O. 2010. Na ive Learning in Social Networks and the Wisdom of Crowds. American Economic Journal: Microeconomics, 2(1), $112-149$.

Golub, Benjamin, \& Jackson, Matthew O. 2012. How Homophily Affects the Speed of Learning and Best-Response Dynamics. The Quarterly Journal of Economics, $\mathbf{1 2 7}(3), 1287-1338$.

Granovetter, Mark. 2005. The Impact of Social Structure on Economic Outcomes. Journal of Economic Perspectives, 19(1), 33-50.

Granovetter, Mark S. 1973. The Strengh of Weak Ties. American Journal of Sociology, 78(6), 1360-1380.

Grogger, Jeffrey, \& Hanson, Gordon H. 2011. Income Maximization and the Selection and Sorting of International Migrants. Journal of Development Economics, 95(1), 42-57.

HAnson, Gordon H. 2006. Illegal Migration from Mexico to the United States. Journal of Economic Literature, 44(4), 869-924.

Ibarraran, Pablo, \& Lubotsky, Darren. 2007. Mexican Immigration and SelfSelection: New Evidence from the 2000 Mexican Census. Chap. 5, pages 159 - 192 of: Borjas, George J. (ed), Mexican Immigration to the United States. University Of Chicago Press.

Jackson, Matthew O., \& Rogers, Brian W. 2007. Relating Network Structure to Diffusion Properties through Stochastic Dominance. The BE Journal of Theoretical Economics, 7, 1-13.

Kaestner, Robert, \& Malamud, Ofer. 2013. Self-Selection and International Migration: Evidence from Mexico. Review of Economics \& Statistics, forthcoming.

Kennan, John, \& Walker, James R. 2011. The Effect of Expected Income on Individual Migration Decisions. Econometrica, 79(1), 211-251.

LAZEAR, Edward P. 1999. Culture and Language. The Journal of Political Economy, 107(6), S95-S126.

Lubotsky, Darren. 2007. Chutes or Ladders? A Longitudinal Analysis of Immigrant Earnings. Journal of Political Economy, 115(5), 820-867. 
Massey, Douglas S., \& Liang, Zai. 1989. The Long-Term Consequences of a Temporary Worker Program: The US Bracero Experience. Population Research and Policy Review, 8(3), 199-226.

Massey, Douglas S., \& Malone, Nolan. 2002. Pathways to Legal Immigration. Population Research and Policy Review, 21(6), 473-504.

Massey, Douglas S., \& Zenteno, René. 2000. A Validation of the Ethnosurvey: The Case of Mexico-U.S. Migration. International Migration Review, 34(3), 766-793.

McKenzie, David, \& Rapoport, Hillel. 2007. Network Effects and the Dynamics of Migration and Inequality: Theory and Evidence from Mexico. Journal of Development Economics, 84, 1-24.

McKenzie, David, \& Rapoport, Hillel. 2010. Self-Selection Patterns in MexicoU.S. Migration: The Role of Migration Networks. Review of Economics and Statistics, 92(4), 811-821.

McKenzie, David, Gibson, John, \& Stillman, Steven. 2013. A Land of Milk and Honey with Streets Paved with Gold: Do Emigrants Have Over-Optimistic Expectations about Incomes Abroad? Journal of Development Economics, forthcoming.

McPherson, Miller, Smith-Lovin, Lynn, \& Cook, James M. 2001. Birds of a Feather: Homophily in Social Networks. Annual Review of Sociology, 27, 415-444.

Moretto, Michele, \& Vergalli, Sergio. 2008. Migration Dynamics. Journal of Economics, 93(3), 223-265.

Munshi, Kaivan. 2003. Networks in the Modern Economy: Mexican Migrants in the U.S. Labor Market. The Quarterly Journal of Economics, 118(2), 549-597.

Orrenius, Pia M., \& Zavodny, Madeline. 2005. Self-Selection among Undocumented Immigrants from Mexico. Journal of Development Economics, 78, 215-240.

Pedersen, Peder J., Pytlikova, Mariola, \& Smith, Nina. 2008. Selection or Network Effects? Migration Flows into 27 OECD Countries, 1990-2000. European Economic Review, 52, 1160-1186.

Redstone, Ilana, \& Massey, Douglas S. 2004. Coming to Stay: An Analysis of the U.S. Census Question on Immigrants' Year of Arrival. Demography, 41(4), 721-738. 
Thijssen, Jacco J. J., Huisman, Kuno J. M., \& Kort, Peter M. 2004. The Effect of Information Streams on Capital Budgeting Decisions. European Journal of Operational Research, 157, 759-774.

UmbliJs, Janis. 2012. The Effect of Networks and Risk Attitudes on the Dynamics of Migration. International Migration Institute Working Paper, 54.

Vergalli, Sergio. 2008. The Role of Communities in Migration Decisions. Labour, 22(3), 547-567.

VigDOR, JACOB L. 2008. Measuring Immigrant Assimilation in the United States. Center for Civic Innovation, Civic Report, $\mathbf{5 3}$.

Winters, Paul, de Janvry, Alain, \& Sadoulet, Elisabeth. 2001. Family and Community Networks in Mexico-U.S. Migration. Journal of Human Resources, 36(1), $159-184$. 


\section{A Appendix: Dynamic Decision Model}

\section{A.1 Derivation of $p^{*}$}

To find a unique value for the threshold number of positive signals $k^{*}$ in Equation (3), we determine the corresponding belief probability $p^{*}$ using dynamic programming. It is possible to find $p^{*}$ by looking at the optimal behavior around $k^{*}$. If $k>k^{*}$ the worker emigrates with certainty, which gives him the expected utility in Equation (1). $k<k^{*}-1$ defines the continuation region, in which she will wait for further signals to arrive. In that case, even the next positive signal will not contain sufficient evidence for a positive migration prospect. The value of migration depends on the belief to obtain a higher income abroad, described by the value function $V_{1}(k)$. The value function for the continuation region has to satisfy the Bellman equation

$$
r V_{1}(k)=\frac{1}{d t} \mathbb{E}\left[d V_{1}(k)\right],
$$

which is derived as follows. The value of lifetime income after migration is $V_{1}(k)$. In the continuation region $V_{1}(k)$ has to equal the expected lifetime income after an instant $d t$, discounted to time $t, V_{1}(k)=\frac{1}{1+r d t} \mathbb{E}\left[V_{1}(k+1)\right]$. Multiplying by $\frac{(1+r d t)}{d t}$ and noting that $\mathbb{E}\left[V_{1}(k+1)\right]-V_{1}(k)=\mathbb{E}\left[d V_{1}(k)\right]$, we get Equation 12$)$.

To determine the value function $V_{1}(k)$, we use the Bellman equation and construct

$$
\begin{aligned}
V_{1}(k) & =\frac{1}{1+r}\left[p(k)\left(\lambda V_{1}(k+1)+(1-\lambda) V_{1}(k-1)\right)\right. \\
& \left.+(1-p(k))\left(\lambda V_{1}(k-1)+(1-\lambda) V_{1}(k+1)\right)\right] .
\end{aligned}
$$

Equation (13) states that the value of the option to migrate now must equal the discounted value of the option after the next signal has arrived. It is helpful to look at the game tree in Figure 2 when interpreting Equation (13). Consider the first half of the RHS of Equation (13). With probability $p(k)$ she gets a good job, so that she is at the upper node of information set 1 . But because the signal from the network is not entirely truthful, she ends up at the upper node of $2 \mathrm{~A}$ with probability $\lambda$ and at the upper node of $2 \mathrm{~B}$ with probability $1-\lambda$. At $2 \mathrm{~A}$ the value function is $V(k+1)$, at $2 \mathrm{~B}$ it is $V(k-1)$. The interpretation of the second half of Equation $(13)$ is analogous.

With some algebraic manipulation, we can write Equation (13) as a second-order difference equation. We first re-write Equation (13) as 


$$
\begin{aligned}
(1+r) V_{1}(k) & =V_{1}(k+1)(2 p(k) \lambda+1-\lambda-p(k)) \\
& +V_{1}(k-1)(p(k)-2 p(k) \lambda+\lambda)
\end{aligned}
$$

Using Equation (2) and defining $\zeta:=\frac{1-p_{0}}{p_{0}}$, the two expressions in parentheses on the RHS reduce to

$$
2 p(k) \lambda+1-\lambda-p(k)=\frac{\lambda^{k+1}+\zeta(1-\lambda)^{k+1}}{\lambda^{k}+\zeta(1-\lambda)^{k}}
$$

and

$$
p(k)-2 p(k) \lambda+\lambda=\frac{\lambda(1-\lambda)\left(\lambda^{k-1}+\zeta(1-\lambda)^{k-1}\right)}{\lambda^{k}+\zeta(1-\lambda)^{k}} .
$$

Inserting these into equation 14 and defining $F(k) \equiv\left(\lambda^{k}+\zeta(1-\lambda)^{k}\right) V_{1}(k)$ yields

$$
F(k+1)-(1+r) F(k)+\lambda(1-\lambda) F(k-1)=0 .
$$

As shown by Thijssen et al. (2004), Equation (15) has the general solution $F(k)=A \beta^{k}$. $A$ is a constant and $\beta$ is a solution to the fundamental quadratic, ${ }^{13}$ which is an upward pointing parabola with a global minimum at $\beta=\frac{r+\mu}{2 \mu}$,

$$
Q(\beta)=\beta^{2}-(1+r) \beta+\lambda(1-\lambda) .
$$

The fundamental quadratic has two real roots

$$
\beta_{1,2}=\frac{1+r}{2} \pm \frac{1}{2} \sqrt{(1+r)^{2}-4 \lambda(1-\lambda)}
$$

The expression under the square root is positive due to $\frac{1}{2}<\lambda<1$.

The general solution to Equation (15) is

$$
F(k)=A_{1} \beta_{1}^{k}+A_{2} \beta_{2}^{k},
$$

where $A_{1}$ and $A_{2}$ are constants. $A_{1}$ will have to be determined from the dynamic optimization problem. For the value function to be well-behaved, we require $A_{2}=0$. If the number of bad signals goes to infinity, i.e. $k \rightarrow-\infty$, the value of the option to migrate

$13 \quad$ A second-order homogeneous linear difference Equation is of the form $y(x+2)+a y(x+1)+b y(x)=0$. The corresponding fundamental quadratic is $\beta^{2}+a \beta+b=0$. 
should go to zero, which can only be ensured if $A_{2}=0$. Hence, the value function for $k<k^{*}$ is

$$
V_{1}(k)=\frac{A_{1} \beta_{1}^{k}}{\lambda^{k}+\zeta(1-\lambda)^{k}} .
$$

The optimization problem has three unknown variables, $A_{1}, p^{*}$ and $k^{*}$. To obtain the threshold belief probability $p^{*}$ and the constant $A_{1}$, we have to consider the two threshold numbers of signals $k=k^{*}$ and $k=k^{*}-1$. At $k=k^{*}$ the worker is indifferent between migrating and waiting. Hence, the value-matching condition $V_{1}\left(k^{*}\right)=\mathbb{E}\left(U\left(k^{*}\right)\right)$ has to be satisfied. At $k=k^{*}-1$, the next good signal will either make him indifferent between migrating and staying, while in the case of a bad signal she will strictly prefer staying. Consequently, starting from a number of signals $k=k^{*}-1$ she will never strictly prefer emigrating after the next signal has arrived, so that $k^{*}-1$ is part of the continuation region. The continuity condition $V_{1}\left(k^{*}-1\right)=\mathbb{E}\left(U\left(k^{*}-1\right)\right)$ states that the value of the option to postpone the migration decision has to equal the expected utility from migration now. These two conditions, together with Equation (3) determine a unique solution for the three unknowns. The value-matching condition yields

$$
A_{1}=\frac{1}{\beta_{1}^{k}}\left(\lambda^{k}\left(w^{G}-M\right)+\zeta(1-\lambda)^{k}\left(w^{B}-M\right)\right) .
$$

The continuity condition is

$$
A_{1}=\frac{1}{\beta_{1}^{k-1}}\left(\lambda^{k-1}\left(w^{G}-M\right)+\zeta(1-\lambda)^{k-1}\left(w^{B}-M\right)\right) .
$$

Equating the continuity condition and the value matching condition and dividing by $\lambda^{k}+\zeta(1-\lambda)^{k}$, we have

$$
\begin{aligned}
p^{*}\left(w^{G}-M\right)+\left(1-p^{*}\right)\left(w^{B}-M\right) & =p^{*} \beta_{1} \frac{\left(w^{G}-M\right)}{\lambda}+\left(1-p^{*}\right) \beta_{1} \frac{\left(w^{B}-M\right)}{1-\lambda} \\
\Leftrightarrow p^{*}\left(w^{G}-w^{B}-\frac{\beta_{1}\left(w^{G}-M\right)}{\lambda}+\frac{\beta_{1}\left(w^{B}-M\right)}{1-\lambda}\right) & =\left(w^{B}-M\right) \frac{\beta_{1}-(1-\lambda)}{1-\lambda} .
\end{aligned}
$$

Dividing by $\left(w^{B}-M\right)$ and solving for $p^{*}$ gives the threshold belief probability

$$
p^{*}=\frac{\beta_{1}-(1-\lambda)}{1-\lambda}\left[\frac{w^{G}-w^{B}}{w^{B}-M}-\frac{\beta_{1}\left(w^{G}-M\right)}{\lambda\left(w^{B}-M\right)}+\frac{\beta_{1}}{1-\lambda}\right]^{-1} .
$$

In the following, we prove that $p^{*}$ is a well-defined probability. 


\section{A.2 Proof: $p^{*}$ Well-Defined.}

Proposition. $3 p^{*}$ is a well-defined probability.

Proof. For $p^{*}$ to be well-defined, it has to be $0<p^{*} \leq 1$. For $p^{*}>0$ to hold, $\frac{\beta_{1}-(1-\lambda)}{1-\lambda}$ and $\left[\frac{w^{G}-w^{B}}{w^{B}-M}-\frac{\beta_{1}\left(w^{G}-M\right)}{\lambda\left(w^{B}-M\right)}+\frac{\beta_{1}}{1-\lambda}\right]$ have to have the same sign. Moreover, $\lambda<1$.

$\frac{\beta_{1}-(1-\lambda)}{1-\lambda}>0$ follows from $\beta_{1}>1-\lambda$.

Note that since $\beta_{1}$ and $\beta_{2}$ are the roots of an upward-pointing parabola with minimum $\frac{1+r}{2}$, it has to hold that $Q\left(\beta_{1}\right)=Q\left(\beta_{2}\right)=0$ and $Q(\varepsilon)<0$ for $\beta_{2}<\varepsilon<\beta_{1}$. $Q(1-\lambda)=-r(1-\lambda)<0$ implies $\beta_{1}>1-\lambda$.

$\left[\frac{w^{G}-w^{B}}{w^{B}-M}-\frac{\beta_{1}\left(w^{G}-M\right)}{\lambda\left(w^{B}-M\right)}+\frac{\beta_{1}}{1-\lambda}\right]>0$ holds as well. Algebraic manipulation yields $\left(1-\frac{\beta_{1}}{\lambda}\right)>$ $\left(1-\frac{\beta_{1}}{1-\lambda}\right)$, which holds by the assumption $\lambda>\frac{1}{2}$. Moreover, $\lambda<1$ by assumption. Consequently, $p^{*}>0$.

Next we show that $p^{*} \leq 1$. This condition is equivalent to

$$
\begin{aligned}
-1 & \leq \frac{w^{G}-w^{B}}{w^{B}-M}-\frac{\beta_{1}}{\lambda} \frac{w^{G}-M}{w_{B}-M} \\
\Leftrightarrow\left(1-\frac{\beta_{1}}{\lambda}\right) M & \leq\left(1-\frac{\beta_{1}}{\lambda}\right) w^{G},
\end{aligned}
$$

which holds by assumption $w^{G}>M$. Hence, $p^{*}$ is a well-defined probability.

\section{B OTHER DATASETS}

Given the available data on Mexican migration in the US, a researcher faces the trade-off between using a large representative dataset with little direct information on networks and without a longitudinal dimension, and small datasets that can offer this additional dimension, but that cannot provide the variation in network characteristics we would need. Using the census, we opted for sample size, which we see as a necessary condition to say anything about diaspora networks.

Other datasets on Mexicans in the US, unfortunately, are too small for our analysis. The household surveys ENET (Encuesta Nacional de Empleo Trimestral), ENADID (Encuesta Nacional de la dinámica demográfica), and the Mexican Family Life Survey (MxFLS) are conducted in Mexico, and have little information on Mexicans that al- 
ready reside in the US. The Mexican Migration Project (MMP), a survey of Mexican migrants that contains both migrants and non-migrants, has some information on family and friends in the US, and on the help of these networks in crossing the border and finding a job. Numerous studies use the MMP to analyze the effect of networks on migration decisions (Munshi, 2003; Bauer et al., 2005; Amuedo-Dorantes \& Mundra, 2007; McKenzie \& Rapoport, 2007; Bauer et al., 2007). The MMP is representative of migration flows to the US (Massey \& Zenteno, 2000), but it is not representative of the stocks. Additionally, it does not have any information on the characteristics of friends and family networks in the US, which is what our analysis requires. 


\section{DATA APPENDiX}

\section{C.1 Education Groups}

For the prediction of the counterfactual wages in Section 4.2 .2 and for the regressions in Section 4.4 we use four broad education groups. Clustering the workers into broad education groups makes the interpretation of the estimates easier and allows us to match the Mexican and the US data. Table 7 shows the education groups for the Mexican and the US census. For the Mexican census we take the variable years of schooling (YRSCHL). The US census distinguishes between 11 education groups (variable EDUC).

TABle 7 - Education groups in the Mexican and US Census

\begin{tabular}{llll}
\hline \hline Nr & Education group & Mexican census & US census \\
\hline & & & \\
1 & High-school dropouts & less than 5 years of schooling & education group 1 \\
2 & Lower secondary education & $5-9$ years of schooling & education groups 2-4 \\
3 & Upper secondary education & $10-12$ years of schooling & education groups 5-7 \\
4 & Third-level education & 13 or more years of schooling & education groups 8-11 \\
\hline \hline
\end{tabular}

\section{C.2 Data Cleaning US census}

In the US census we exclude the following observations:

- younger than 18 and older than 64 years,

- younger than 18 at the time of immigration,

- if still enrolled in education $(\mathrm{SCHOOL}=2)$,

- self-employed people,

- with an annual wage income (INCWAGE) higher than 200,000 USD, as these were clear outliers,

- living in Hawaii and Alaska,

- if born to American parents in Mexico (CITIZEN=1),

- with unknown income, 
- who work less than 7 hours a week (UHRSWORK) or less than 8 weeks a year (WKSWORK1, not available for 1980), or if any of these is missing,

- if they live in group quarters (hospitals, prisons, etc; $G Q=3$ or $G Q=4$ )

- if they moved to a district (CONSPUMA) with at least 20 Mexicans.

To make wages comparable between the US and Mexico, we use monthly wages.

Explain here why monthly and not hourly or weekly

To obtain monthly wages, we divide the annual wages by 12 . Since not all Mexicans work throughout the entire year and work full time, we adjust the income by weeks worked per year (WKSWORK1) and by hours worked in a typical workweek (UHRSWORK). In the 1980 census we obtain the adjusted monthly income by multiplying the nominal monthly income by 40 (the full time equivalent), and divide it by the actual hours worked. From 1990 onward we also have information on the average weeks per year, so that the adjusted income is calculated as

$$
\text { adjusted income }=\text { nominal income } \frac{52 * 40}{\text { weeks worked } * \text { hours worked }} .
$$

In the ACS the number of weeks worked comes in 6 categories, and we use the midpoints for each category $(7 ; 20 ; 33 ; 43.5 ; 48.5 ; 51)$. In some rare cases the denominator in Equation (17) is very small - if the person has worked few hours and few weeks and we drop every observation that yields an adjusted wage income of more than 15,000 USD per month.

\section{C.3 MeXicAN CENSUS}

We use the $10 \%$ files of the Mexican census in 1990, 2000, and 2010 for the estimation of counterfactual wages. The following observation are excluded:

- younger than 18 and older than 64 years

- more than 100 or less than 10 hours of work per week (HRSWORK1)

- self-employed

Monthly income is taken from the variable INCEARN. As with the US census, we adjust monthly income by hours of work by multiplying it with 40 and dividing it by the usual hours of work per week (HRSWORK1). To convert the monthly wage into PPP 
dollars, we divide the adjusted wage by a PPP factor (price level Mexico over Price level US) and the exchange rate (pesos per dollar). ${ }^{14}$

14 The PPP factor is the amount of goods in return for one dollar in the US over the amount of goods in return for one dollar in Mexico. The PPP factor was 0.48 in 1990, 0.63 in 2000, and 0.68 in 2010. The exchange rates were 2.83 pesos per dollar in 1990, 9.2845 in 2000, and 12.6287. Sources: Penn World Tables (PPP) Mexican Central Bank (Exchange Rate). 
Table 8 - Counterfactual Wages: Correlations

\begin{tabular}{lrrrrrrrr}
\hline \hline & \multicolumn{9}{c}{$\mathbf{2 0 0 0}$} & \multicolumn{5}{c}{$\mathbf{2 0 1 0}$} \\
& Baseline & PSM & Internal & Heck & Baseline & PSM & Internal & Heck \\
\hline Baseline & 1 & & & & 1 & & & \\
PSM & 0.98 & 1 & & & 0.99 & 1 & & \\
Internal & 0.90 & 0.92 & 1 & & 0.92 & 0.93 & 1 & \\
Heckman & 0.95 & 0.94 & 0.80 & 1 & 0.98 & 0.98 & 0.89 & 1 \\
\hline \hline
\end{tabular}

Note: The table displays the correlations between different predictions of counterfactual wages of Mexicans in the US.

\section{Robustness CHECKS}

\section{D.1 Counterfactual Wages}

We predict counterfactual wages using three approaches: a sample based on propensity score matching, a sample consisting of internal migrants, and a Heckman selection model that accounts for selection into employment. Table 8 shows the correlation coefficients for the counterfactual wages on the entire sample of Mexicans in the US. The correlation coefficients are remarkably large, which gives us confidence that the straightforward prediction of Mexican wages does not suffer from severe selection bias.

\section{D.2 PPP CONVERSION OF US WAGES}

In the baseline scenario we construct our dependent variable as the difference between Mexican and US wages, thereby adjusting Mexican wages for purchasing power. Hence, the wage difference is the difference between the consumption values of wages in Mexico and the US. US wages of Mexican immigrants, however, may not reflect the true purchasing power, if immigrants consume a fraction of their income in their home country, send money home, or save money in order to consume at home at a later stage. Dollars earned in the US can be adjusted for purchasing power in Mexico as follows. Let $s$ be the fraction of income consumed in Mexico and $P P P<1$ the price level in Mexico compared to the States. The adjusted wage is then

$$
\tilde{w}_{U S}=w_{U S}\left(1-s+\frac{s}{P P P}\right) .
$$

If the fraction of income consumed in Mexico is greater than zero, then the purchasing power of a dollar is strictly greater than one. To demonstrate the robustness of our results, we re-calculate the wage differences, using values $s=\{0.2,0.5,1\}$, and re-estimate model 


\section{Table 9 - Estimation Results when a Share of US Income is Consumed in MEXICO}

Dependent variable: losses from emigration per month

\begin{tabular}{ccccc}
\hline \hline & \multicolumn{2}{c}{ Full sample } & \multicolumn{2}{c}{ Positive incomes } \\
& $(1)$ & $(2)$ & $(3)$ & $(4)$ \\
& OLS & 2SLS & OLS & 2 SLS \\
\hline $20 \%$ & $5.426^{* * *}$ & $6.439^{* * *}$ & $6.189^{* * *}$ & $6.439^{* * *}$ \\
& {$[0.886]$} & {$[0.955]$} & {$[0.964]$} & {$[0.955]$} \\
$50 \%$ & $6.277^{* * *}$ & $7.451^{* * *}$ & $7.157^{* * *}$ & $7.451^{* * *}$ \\
& {$[1.027]$} & {$[1.106]$} & {$[1.115]$} & {$[1.106]$} \\
$100 \%$ & $7.695^{* * *}$ & $9.138^{* * *}$ & $8.770^{* * *}$ & $9.138^{* * *}$ \\
& {$[1.261]$} & {$[1.356]$} & {$[1.368]$} & {$[1.356]$} \\
\hline \hline
\end{tabular}

Note: The table displays the IV estimation results for Equation 4 for different shares of consumption in Mexico. A share of $20 \%$ means that $20 \%$ of income earned in the US is consumed in Mexico. In all regressions we control for age, age squared, education, marital status and average wages of US workers. Columns (1) and (2) use the full sample, (3) and (4) use all workers with a positive income. Standard errors, clustered at the conspuma-level, are displayed in parentheses. ${ }^{*} \mathrm{p}<0.1, * * \mathrm{p}<0.05,{ }^{* * *} \mathrm{p}<0.01$.

with the new dependent variables. Table 9 shows that the estimated coefficients are even larger in magnitude once we account for the purchasing power US wages in Mexico. In the baseline results in Table 5 we under-estimate the effect of networks on the success of migrants. As we are not able to observe the share of consumption in Mexico, the analysis is limited by the assumption that $s$ is constant across groups. 